\title{
Contribution
}

Michihito Ando* and Reo Takaku

\section{Affordable False Teeth: The Effects of Patient Cost Sharing on Denture Utilization and Subjective Chewing Ability}

DOI 10.1515/bejeap-2015-0194

Published online June 2, 2016

\begin{abstract}
We evaluate the impact of patient cost sharing on the use of dentures and subjective chewing ability exploiting a sharp reduction in the coinsurance rate, the percentage of costs born by the user, from $30 \%$ to $10 \%$ at the age of 70 with a regression discontinuity design. Using data from the Japanese Study of Aging and Retirement (JSTAR), we find that the utilization rate of dentures increases from approximately $50 \%$ to $63 \%$ around the threshold, implying that the extensive margin elasticity of denture usage with respect to the coinsurance rate is about -0.41 . In addition, we find this jump is almost entirely due to the change in the rate among women. On the other hand, we do not find a significant improvement in self-reported chewing ability, although chewing ability may not be the only social benefit from dentures. Our empirical findings are also confirmed by complementary analysis with randomization tests.
\end{abstract}

Keywords: oral health, dentures, price elasticity, regression discontinuity design, cost sharing, randomization test

JEL classification: H51, I12, I13, I18

\section{Introduction}

There is a rapidly increasing body of literature on the impact of the introduction of health insurance on healthcare utilization and health. ${ }^{1}$ On the other hand, the impact

1 In addition to the literature referred to in Levy and Meltzer (2008), the recent expansion of universal coverage in Massachusetts and Oregon HIE have given rise to further literature. On the

*Corresponding author: Michihito Ando, National Institute of Population and Social Security Research, Hibiya Kokusai Building 6th Floor, 2-2-3 Uchisaiwaicho, Chiyoda-ku, Tokyo, 100-0011, Japan, E-mail: andou-michihito@ipss.go.jp

Reo Takaku, Institute for Health Economics and Policy, No.11 Toyo-kaiji Bldg, 1-5-11, Nishi-Shinbashi, Minato-ku, Tokyo, 105-0003, Japan, E-mail: reo.takaku@ihep.jp 
of patient cost sharing on these outcomes has not been explored sufficiently (Baicker and Goldman 2011). In particular, there is limited evidence on the effects of patient cost sharing on a common and important type of primary care: dental care services. ${ }^{2}$

Although dental care costs account for only a part of total health care expenditure, we should not ignore the association between oral health and quality of life. The WHO asserts that tooth loss may have profound impact on quality of life and nutrition intake, pointing out a link between oral disease and general health conditions (Kwan and Petersen 2010). When it comes to the economic burden of oral diseases, one study mentions that oral diseases are the fourth most expensive category of diseases to treat in most industrialized countries (Petersen et al. 2005) and another study estimates that the global economic cost of dental diseases reached 442 billion USD in 2010 (Listl et al. 2015). In addition, an economic study (Glied and Neidell 2010) shows that improvement of oral health condition is also associated with increased wages among women, though there are insufficient number of wellconducted studies on this issue (Singhal, Correa, and Quinonez 2013).

To the best of our knowledge, no experimental studies have investigated both the impact of health insurance introduction and the impact of patient cost sharing among the elderly population in the field of dental care and dental health, despite increasing dental care expenditures due to rapid ageing. For instance, two important health insurance experiments that exploit randomization (RAND Health Insurance Experiment and Oregon Health Insurance Experiment, hereafter RAND HIE and Oregon HIE) excluded dental care utilization among the elderly from their investigations. ${ }^{3}$

When it comes to quasi-experimental studies, some studies focus on the impact of health insurance coverage on dental care utilization among children and adolescents (Wang, Norton, and Gary Rozier 2007), working-age individuals (Choi 2011), adult Medicaid beneficiaries (Wallace et al. 2011; Nasseh and Vujicic 2013), the elderly population (Kreider et al. 2015) and non-elderly adults (Decker

Massachusetts Health Care reform, the results show significant improvement of health in both subjective measure (Courtemanche and Zapata 2014) and objective measures such as mortality (Sommers, Long, and Baicker 2014). On the other hand, the results from Oregon HIE are quite different. Finkelstein et al. (2012) observed better self-reported physical and mental health, but their later paper shows there is no improvement in objective health indicators such as blood pressure (Baicker et al. 2013).

2 There are some notable exceptions such as Hay, Bailit, and Chiriboga (1982), Manning et al. (1985, 1986), Mueller and Monheit (1988), Ikenwilo (2013) and Meyerhoefer, Zuvekas, and Manski (2014).

3 RAND HIE excluded the elderly population (Newhouse 1993), while dental utilization among adults is studied. In Oregon HIE, vision and nonemergency dental care were not covered (Finkelstein et al. 2012). 
and Lipton 2015). For a review of the impact of insurance coverage on dental care utilization, see also the literature introduced in Decker and Lipton (2015).

The impact of cost sharing, however, has not been directly studied and it may be different from the impact of the insurance coverage itself. Note that the impact of health insurance coverage and the impact of cost sharing are closely related but different issues because the former may include the impact of reimbursement methods (e.g. refund or in-kind) and payment of insurers while the latter is in general restricted to the effect of patients' copayment.

This paper investigates the impact of an exogenous reduction in cost sharing on the utilization of dentures. More concretely, we exploit a discontinuous reduction in the coinsurance rate, which is the ratio of patient cost sharing to total cost, at the age of 70 in the Japanese public health insurance system. One reason denture utilization is worth investigating is that denture treatment is one of the most common dental services among the elderly population in developed countries. For example, Petersen and Yamamoto (2005) summarize the previous literature and point out that from one-third to half of all elderly people wear full dentures and up to three-quarters wear removable full or partial dentures in some developed countries.

In Japan, according to MHLW (2011), an official survey of the Ministry of Health, Labour and Welfare (MHLW), 41.9\% of people aged 70 to 74 wear partial dentures and $24.3 \%$ wear full dentures. Matsuyama et al. (2014) report that two-thirds of elderly respondents who have 19 or fewer teeth wear dentures. ${ }^{4}$ According to the 2013 Estimates of National Medical Care Expenditure, annual dental care spending in Japan for the elderly population (individuals 75 years old and older) amounts to 425 billion JPY (3.54 billion USD if $1 \mathrm{JPY}=120 \mathrm{USD}$ ). Although this accounts for only $3.2 \%$ of total public health care expenditures for the elderly population, $14 \%$ of the dental care expenditures for this population are used on the provision of prosthetic care such as dentures. ${ }^{5}$

Nonetheless, there have been few economic studies on the relationship between public health insurance and denture utilization. Because Japanese public

4 Their results are from a survey conducted in one Japanese city. Matsuyama et al. (2014) also find some individuals with an insufficient number of teeth who do not wear dentures due to their low income, whereas the utilization rate of dentures is high in the lowest income population due to public assistance and other social programs.

5 In May 2014, total spending on prosthetic care among the elderly population was 4.9 billion JPY (Survey of Medical Care Activities in Public Health Insurance 2014). Based on this value, we estimate annual spending of 58.9 billion JPY. 
health insurance covers dentures for all elderly people but with different patient cost sharing settings, our study can provide unique evidence on this topic. ${ }^{6}$

In addition to such a high utilization rate among the elderly, there is another reason that the demand for dentures is worth investigating. Wearing a denture is a dental care service that is generally specific to the elderly population (i. e. children and working-age adults seldom wear dentures). This suggests the results from previous studies that focus on the dental care utilization among children and the working-age population cannot be directly applied to the demand for dentures. In particular, the results from RAND HIE constitute a fundamental contribution to our understanding of the impact of cost sharing on dental care utilization, but they may not be necessarily relevant to the demand for prosthetic dental care such as dentures since RAND HIE excludes the elderly population.

To explore the causal effect of patient cost sharing on denture utilization, we utilize a regression discontinuity $(\mathrm{RD})$ design that exploits the sharp reduction of the coinsurance rate from $30 \%$ to $10 \%$ at the age of 70 years in Japanese public health insurance and takes age in months as an assignment variable. Our institutional settings and identification strategy are for the most part the same as those employed by Shigeoka (2014a), although he does not investigate the impact on dental care utilization and oral health. Nishi et al. (2012) also adopt a similar RD design to estimate the effect of reduced cost sharing on out-of-pocket medical spending and physical and mental health, although their assignment variable is age in years, not months. Fukushima et al. (2015) more directly extend Shigeoka (2014a)'s study with the same RD design using richer outcome variables, but they also do not examine dental care and dental health. Finally, we conduct additional statistical tests for RD estimation based on randomization inference following Cattaneo, Frandsen, and Titiunik (2014) in order to take into account a relatively small sample size.

Our findings can be summarized in three points. First, we find a significant jump in the utilization rate of dentures at the age of 70 . The central estimate from RD estimation implies that the probability of wearing dentures increases by $13 \%$ just after becoming 70 years old. Since the average utilization rate before age 70 is around $50 \%$, the implied elasticity of denture utilization with respect to the coinsurance rate is approximately -0.41 , which is twice as large as the price elasticity of outpatient visits at the same threshold presented by Shigeoka (2014a) and Fukushima etal. (2015). Second, we find that responses to cost

\footnotetext{
6 Note that public insurance coverage and cost sharing for denture service seem to differ significantly in developed countries. For instance, while Medicare in the US does not cover denture, the UK and Germany do. Cost sharing for dentures in the U.K. and Germany, however, is in general much higher than in Japan.
} 
sharing are considerably heterogeneous across gender: the elasticity of denture utilization with respect to the reduction of the coinsurance rate is high for women but close to zero for men. This result is consistent with the finding of Manning and Phelps (1979) who show the price elasticity of dental care among white adults is higher in women than in men. Third, we investigate the impact of patient cost sharing on self-reported chewing ability ${ }^{7}$, but find no evidence that reduced cost sharing improves it. Given that one of the primary objectives of wearing dentures is the improvement of chewing ability (Japan Prosthodontic Society ${ }^{8}$ ), this could be an appropriate outcome to evaluate the benefit of reduced cost sharing for dentures. On the other hand, it should be noted that the chewing ability is not the sole benefit of dentures. Improvement of pronunciation and facial expression can also be important outcomes. Without exploring effects on these outcomes, the overall costs and benefits of reduced cost sharing for dentures remain unclear.

This paper is organized as follows. In the next section we conduct a short review of prior literature on the impact of patient cost sharing on dental care utilization and describe denture utilization and relevant institutional settings in Japan. In Section 3 we explain our identification strategy and data. In Section 4 we present estimation results and several robustness checks. In Section 5 we state our conclusions.

\section{Background}

\subsection{Cost Sharing and Dental Care}

One of the most important contributions to understanding the relationship between patient cost sharing and dental care is that of the RAND HIE. Manning et al. (1986) summarize the probability of dental care utilization under four alternative insurance plans and show how health insurance affects dental care utilization. Numerically, the probability of utilization was $68.8 \%$ under a free care plan and $48.3 \%$ under a $95 \%$ coinsurance rate plan. Since the assignment of each insurance plan was random, the differences in the utilization rate can be interpreted as the causal effect of the extent and nature of health insurance coverage. Importantly, Manning et al. (1986) also argue that most of the differences in response to differing insurance plans can be attributed to a differential response between a $25 \%$ plan

7 In our study, chewing ability is originally measured with a 5-grade scale and we convert this indicator to two binary indicators.

8 http://hotetsu.com/index.html (Accessed on June 5, 2014). 
and a free plan because large differences are not observed between other plans. This finding implies that dental care utilization is not elastic with respect to patient cost sharing, but elastic with respect to to insurance coverage.

Sintonen and Linnosmaa (2000) review non-experimental studies on dental care and conclude that estimated price elasticities are broadly consistent with expectations. ${ }^{9}$ Among these studies, Mueller and Monheit (1988) present similar results to those of the RAND HIE. Using nationally representative data in the United States, Mueller and Monheit (1988) suggest that patient response to the extent of coverage is smaller than patient response to the presence or absence of insurance coverage. Meyerhoefer, Zuvekas, and Manski (2014) also reach the same conclusion: Using the 2001-2006 Medical Expenditure Panel Survey, they find that dental coverage significantly increased the probability of using preventive care by $19 \%$ and the probability of using restorative services by $11 \%$ to $16 \%$, whereas these forms of dental care utilization were not sensitive to out-of-pocket costs determined by insurance eligibility. These studies, however, are likely to derive biased estimates since they do not exploit experimental or quasi-experimental research designs. Although Meyerhoefer, Zuvekas, and Manski (2014) rely on a correlated random effects (CRE) model to address a variety of potential measurement errors ${ }^{10}$, they also mention that these biases cannot be ruled out if the measurement error process is not time-invariant.

On the other hand, a recent quasi-experimental study suggests that dental care utilization is responsive to patient copayment: Ikenwilo (2013) presents difference-in-differences analysis on the impact of free dental checkups in Scotland in 2006 using the rest of the UK as a control group ${ }^{11}$, showing that the abolition of user fees led to a modest increase in preventive dental care utilization among the adult population. ${ }^{12}$ In addition, some quasi-experimental studies indicate that increased Medicaid fees improve access to dental care services among children via increased dentist participation in Medicaid (e. g. Eklund, Pittman, and Clark 2003; Hughes et al. 2005; Decker 2011; Buchmueller, Orzol, and ShoreSheppard 2015). Buchmueller, Miller, and Vujicic (2014) also find that the

9 Kiil and Houlberg (2014) present a systematic review of the literature that investigated the impact of copayment on healthcare demand and redistribution in the period from 1990 to 2011. However, their review finds no study on dental care services.

10 Measurement errors accrue from the fact that insurance status and the amount of out-ofpocket costs may be misreported. In addition, the shadow price of healthcare utilization can be an important omitted variable in a healthcare demand equation.

11 Since anyone needing dental check-up services through the NHS had been required to pay 80 percent of the check-up cost, the reduction of out-of-pocket cost due to the abolition of user fees was substantial.

12 Mean age is 46.33 (S.D. 18.43). 
expansion of Medicaid dental coverage for adults causes an increase in dentists' participation in Medicaid and an increase in the supply of services to publicly insured patients. These studies suggest that the reduction in non-monetary cost (i. e. improved accessibility to dentists who accept Medicaid patients) also increases dental care utilization.

\subsection{Denture Utilization in Japan}

In Japan, a national-level public health insurance system allows everyone to receive dental care with relatively low out-of-pocket costs. Among the OECD countries, Japan seems to have one of the most accessible systems when it comes to the provision of dental care services. This is because Japanese public health insurance offers the same coinsurance rate for the utilization of dental care services as for the utilization of other healthcare services, while many countries restrict the coverage for dental care services. As a result of such a generous policy, the utilization rate of dental care services in Japan is extraordinarily high. The number of dentist consultations per capita in Japan was highest in the OECD countries $^{13}$ and out-of-pocket dental expenditure per capita was only half of the OECD average (OECD 2011).

The public health insurance also covers the utilization of dentures. Under the universal fee schedule set by the national government that determines the official reimbursement prices paid by insurers to medical facilities, the amount of reimbursement for complete dentures throughout Japan was 21,000 JPY in 2014. ${ }^{14}$ Of the total healthcare costs for denture treatment, patients have to bear between $10 \%$ and $30 \%$ depending on their age and household income. Unlike the United States, out-of-pocket costs do not vary among the types of health insurance. ${ }^{15}$ In addition, if the amount of out-of-pocket expenditure reaches a certain amount, patients, in principle, do not have to pay any further under a stop-loss scheme. ${ }^{16}$

Public assistance and a program for people with disabilities are the two exceptions to this patient cost sharing system. First, there is no out-of-pocket cost for dentures for those who receive public assistance. Empirically, Matsuyama

13 The value is 3.2 in 2009 and this value was far above 2.3 in Israel, which is the second highest country (OECD 2011). The OECD average was only 1.3 .

14 One JPY is approximately 0.012 USD at the end of 2014. For partial dentures, the amounts of reimbursement varies from 5,600 JPY to 13,400 JPY based on the number of dentures.

15 There are over 3000 health insurance providers, but the benefit packages are almost the same. For a further explanation of the public health insurance system in Japan, see Ikegami et al. (2011). 16 Stop-loss in Japan is monthly, not yearly. 
et al. (2014) find the eligibility for public assistance may increase the probability of wearing dentures, showing the utilization rate of dentures is higher among elderly people in the lowest income group than in the other income groups. In addition, co-payment for dental care is often reduced for the disabled through programs implemented by the national and local governments, although there is large regional variance in the generosity of local programs.

Under these multi-layered programs, the elderly population in Japan can generally obtain dentures without significant financial constraint. Ueno et al. (2008) confirm that the number of natural teeth declines according to age, but the number of total functional teeth that include dentures remains stable because the number of artificial teeth on removable prostheses increases with age. Ueno et al. (2012) find no difference in the number of total functional tooth units (total-FTUs ${ }^{17}$ ) across educational attainment, whereas the number of natural teeth is considerably lower in adults of low educational attainment. Interpreting these findings, Ueno et al. (2012) conclude "In fact, any Japanese person can afford to have dentures made regardless of their SES, because it is relatively inexpensive under the Japanese universal public health insurance system". 18

\subsection{Reduction of Cost Sharing at Age 70}

In Japan, the coinsurance rate for the enrollees of public health insurance before age 70 is $30 \%$ if they are not eligible for additional subsidies from central or local governments. However, this rate sharply decreases to $10 \%$ after the individual's 70th birthday in the most cases. Table 1 summarizes the system of patient cost sharing for outpatient care during our sample period. ${ }^{19}$ It shows

17 Total-FTUs is defined as the number of pairs of opposing natural teeth and artificial teeth on implant-supported, fixed, and/or removable prostheses in posterior teeth occlusion (Ueno et al. 2012).

18 On the other hand, Matsuyama et al. (2014) report that people in the low-income population excluding welfare recipients are less likely to wear dentures even if they do not have a sufficient number of natural teeth, although this may be attributed to confounding factors other than low income.

19 Although not relevant to our research because we use a sample of elderly people aged 70-74, the cost sharing scheme presented in Table 1 is to a large extent unchanged for the elderly aged 75 or more. However, health insurance coverage for the population over age 75 is integrated into a different scheme called Latter-Stage Elderly Healthcare System (LSEHS). In addition, since April 2014, the coinsurance rate for the age of 70 years and over with middle- or low-incomes has increased from $10 \%$ to $20 \%$, but this increase only applies to those who had not already turned 70 when the change went into effect. 
Table 1: Cost sharing for outpatient care utilization: before and after age 70 (2006.10-2014.3).

\begin{tabular}{lrrrrr}
\hline Income level & \multicolumn{2}{c}{ Coinsurance rate } & $\begin{array}{r}\text { Monthly stop-loss } \\
\text { (age 70-74, JPY) }\end{array}$ & $\begin{array}{r}\text { Share in the elderly } \\
\text { aged 70-74 (2010) }\end{array}$ \\
\cline { 2 - 3 } & Before age 70 & After age 70 & & & $8.70 \%$ \\
\hline High & $30 \%$ & $30 \%$ & 44,400 & $\mathbf{9 1 . 3 0 \%}$ \\
Middle & $30 \%$ & $10 \%$ & 12,000 & 8,000 \\
Low & & & & \\
\hline
\end{tabular}

Notes: Individuals and their families are placed in the "high" income level category if at least one household member's taxable annual income is 1.45 million JPY or more (for those enrolled in municipality-based health insurance), or if their standard monthly remuneration is over 280,000 JPY (for those enrolled in employment-based health insurance). Individuals and their families are placed in the "low" income level category if they are exempted from paying the Local Residential Tax (i. e. The Japanese local personal income tax). All others are included into the "middle" income level category. According to the official statistics of the Ministry of Health, Labour and Welfare (MHLW), the percentage of high-income individuals among the elderly aged 70 to 74 was only $8.7 \%$ in 2010 ( $7.9 \%$ for enrollees with municipality-based insurance and $13.6 \%$ for enrollees with employment-based health insurance). The calculation of this percentage is based on The Report on the National Health Insurances (Kokumin kenkou hoken jigyo jokyo houkokusyo) and The Annual Report on Health Insurance and Sailors Insurance (Kenko hoken Senin Hoken Jigyo nenpo). Monthly stop-losses in this table are for people aged 70 to 74. Monthly stop-losses for people aged 69 and under are in most cases much larger than those in the table (i.e. 35,400, 80,100, 150,000 JPY for low, middle, and high income individuals respectively. One JPY was approximately 0.012 USD at the end of 2014.

that more than $90 \%$ of elderly people are exposed to this sharp reduction in the coinsurance rate.

There are, however, two institutional complications. First, the coinsurance rate remains $30 \%$ for those with high incomes and we cannot exclude this group from our sample due to the lack of precise taxable income information in our dataset. We nonetheless argue that the percentage of the total population aged $70-74$ in the high-income category is relatively low (8.7\% in 2010) and this problem should not seriously affect our estimates. We will discuss this problem further in Section 3.

Second, there are income-based monthly stop-losses as is shown in Table 1. The stop-loss scheme drastically decreases out-of-pocket expenditures for patients with high healthcare costs because the marginal increase in cost sharing is almost zero once out-of-pocket expenditures exceed their stop-loss level. The stop-loss scheme, however, should not pose a serious problem in our identification strategy because out-of-pocket costs for publicly insured dentures in general do not exceed such limits even for those with low-incomes with the 
lowest stop-loss. ${ }^{20}$ In addition, although reaching the stop-loss due to other healthcare expenses implies practically free or cheaper than usual publiclyinsured dentures, such cases seem to be rare because of relatively high monthly stop-loss even after age $70 .^{21}$

\section{Estimation and Data}

\subsection{Identification Strategy}

Following Shigeoka (2014a), we exploit a discontinuous change in the coinsurance rate at the age of 70 in order to identify the effect of reduced cost sharing on denture usage. As is explained in Section 2.2, there is a sharp reduction in the coinsurance rate from $30 \%$ to $10 \%$ at the age of 70 in our sample period. This is an exogenous variation that is not manipulable by the elderly around this threshold. Fortunately, there are no other clear institutional thresholds that could generate confounding discontinuities at age 70. People right around this threshold can thus for the most part be viewed as if they had been randomly assigned to two systems with different of coinsurance rates.

Our estimation equation, which is also akin to the equation in Shigeoka (2014a), is a standard regression discontinuity (RD) model:

$$
Y_{i}=\beta D_{i}+f\left(V_{i}\right)+\mathbf{X}_{i}^{\prime} \gamma+\varepsilon_{i},
$$

where $Y_{i}$ is an indicator variable that takes the value one if individual $i$ uses a denture and otherwise zero, $D_{i}$ is a treatment dummy variable that takes the

20 Total out-of-pocket expense for publicly insured complete dentures is approximately 3,500 JPY when the coinsurance rate is $10 \%$, according to several resources on denture fees.

21 For the elderly aged 70 and over, the monthly stop-loss in Table 1 apply to the sum of all out-of-pocket medical and dental costs. On the other hand, for people under age 70, the monthly stop-loss applies to out-of-pocket costs in each hospital or dentist as long as the costs do not exceed 21,000 JPY. Thus the possibility of reaching the stop-loss is much higher for people aged 70 and over. However, average monthly out-of-pocket costs per capita for medical outpatient care, dental care and drugs are only 3,148 JPY for people aged 70-74 even if we assume that people in this age cohort must pay exactly $10 \%$ of the total healthcare costs with no stop-loss (our own calculation based on Estimates of National Medical Care Expenditure 2013). It is therefore reasonable to assume that denture utilization just after age 70 is not seriously affected by the more generous stop-loss scheme that goes into effect at this age. Relying on calculation with administrative data from hospitals and clinics, Shigeoka (2014a) also argues that the effect of the monthly stop-loss on healthcare overutilization is much smaller in Japan than in RAND HIE and most US health insurance systems. 
value one if the age of individual $i$ is 70 or over 70. $f\left(V_{i}\right)$ is a continuous function of the standardized age in months $V_{i} . V_{i}$ is calculated as the age in months minus 840 months $(70 \times 12$ months) and serves as an assignment (or running) variable in our RD design. $\mathbf{X}_{i}$ is a vector of pre-determined covariates and $\varepsilon_{i}$ is an error term. $\beta$ is our parameter of interest, that is, the causal effect of the reduction in the coinsurance rate on the probability of denture utilization.

If the assumption of local randomization around the threshold is plausible, we do not need to include covariates $\mathbf{X}_{i}$ in our model in order to obtain an unbiased estimate of $\beta$. We can thus use $\mathbf{X}_{i}$ for an indirect check of our identifying assumption as well as the improvement of precision (Lee and Lemieux 2010). When it comes to the continuous function $f\left(V_{i}\right)$, we use a polynomial whose functional form is allowed to change before and after the threshold while imposing continuity at the threshold. That is, $f\left(V_{i}\right)=\alpha+\sum_{i=1}^{P}\left(\theta_{0 p} V_{i}^{p}+\theta_{1 p} D_{i} V_{i}^{p}\right)$, where $P$ is the order of polynomial and $\theta_{0 p}$ and $\theta_{1 p}$ are the coefficients of polynomial terms.

We also use several different bandwidths to limit the sample around the threshold. As Hahn, Todd, and Van der Klaauw (2001) suggest, linear RD estimation with a small bandwidth is most preferable if the sample size is sufficiently large around the threshold. Gelman and Imbens (2014) also argue that higher-order polynomials such as third, fourth and higher should not be used in RD designs. In line with these recommendations, we in general prefer $\mathrm{RD}$ estimates based on a linear or quadratic polynomial and a smaller bandwidth, but we also provide several combinations of a bandwidth and a polynomial and examine how robustly estimation results hold up against different choices of bandwidth and polynomial. In addition, due to the discreteness and limited range of our assignment variable, we do not use the methods of selecting optimal bandwidth in RD estimation proposed by Imbens and Kalyanaraman (2012) and Calonico, Cattaneo, and Titiunik (2014). That is, because our assignment variable is age in months and this variable consists of only 120 discrete values (780 to 899 or age 65 to age 74 ) at maximum, we prefer to provide RD estimates with varying bandwidths rather than to present a single RD estimate with an "optimal” bandwidth based on additional assumptions. Akaike Information Criteria (AIC) is presented in baseline estimation results for reference, but in line with the argument made by Gelman and Imbens (2014) we do not choose the "best" polynomial form based on AIC.

For the calculation of standard errors, as Lee and Card (2008) point out, the conventional standard errors that do not take into account the discreteness of the assignment variable tend to overstate the precision of the estimates. We therefore follow their recommendation and use standard errors that are clustered by age in months. 
Finally, even if people around the age-70 threshold cannot manipulate their assignment of the two coinsurance rates, there is some possibility that people just before the age of 70 years are aware of the reduction of their coinsurance rate in the near future and refrain from buying dentures before they become 70 years old. This behavior may result in overestimation (or underestimation) of a true causal effect (Lee and Lemieux 2010; Shigeoka 2014a). Although dentures are a kind of "health stock" and people do not have to purchase them frequently ${ }^{22}$, there is still some possibility that people with broken dentures refrain from buying a new one until they reach the age of 70. In graphical analysis and robustness checks, we investigate this issue by examining the distribution of the denture utilization rate around the threshold and by presenting "donut-RD" estimates (Barreca et al. 2011), which are obtained by dropping possibly noisy observations around the threshold and then recovering their counterfactual distributions by extrapolation.

\subsection{Randomization Inference}

There is another concern about statistical significance tests with RD designs. Because the sample size in our study is relatively small around the threshold, we also use randomization inference based on the approach proposed by Cattaneo, Frandsen, and Titiunik (2014). Building on Rosenbaum (2002; 2010), Cattaneo, Frandsen, and Titiunik (2014) propose a randomization test for RD designs where the assumption of local randomization is straightforwardly applied to a subsample around a threshold.

First we assume that observations around a certain neighborhood of the threshold can be seen as having been randomly allocated to the left or right side of the threshold. In other words, we assume that the coinsurance rates of $10 \%$ and $30 \%$ are randomly assigned to observations in this subsample. We then want to know whether the standard difference-in-means estimator $\hat{\beta}=\bar{Y}_{i: D_{i}=1}-\bar{Y}_{i: D_{i}=0}$ is significantly different from zero or not, where $\bar{Y}_{i: D_{i}=1}$ is the average of $Y_{i}$ for the treated $\left(D_{i}=1\right)$ and $\bar{Y}_{i: D_{i}=0}$ is the average of $Y_{i}$ for the untreated $\left(D_{i}=0\right)$.

In a simple randomization test, we can make the distribution of a test statistic $T(\mathbf{W}, \mathbf{Y})=\hat{\beta}=\bar{Y}_{i: W_{i}=1}-\bar{Y}_{i: W_{i}=0}$ with observations in this subsample, where the assignment vector $\mathrm{W}$ indicates which observations are labeled as "treated" $\left(W_{i}=1\right)$ and "untreated" $\left(W_{i}=0\right)$ in the calculation of a test statistic. ${ }^{23}$ In a

22 In addition, a patient in Japan cannot ask dentists to make a new publicly insured denture if he or she has already received one within the last 6 months.

23 Notations here generally follow Section 4.2 in Imbens and Wooldridge (2009), which provides a simple description of randomization inference. 
conventional randomization test, we can deduce the exact distribution of $T(\mathbf{W}, \mathbf{Y})$ by calculating $T(\mathbf{W}, \mathbf{Y})$ with all possible combinations of $W_{i}$ in the assignment vector $\mathbf{W}$ with a known assignment mechanism. We then test the statistic $\hat{\beta}$ with the distribution of $T(\mathbf{W}, \mathbf{Y})$ under the sharp null hypothesis of no effect.

A key presumption for this test is that a researcher knows, or at least can estimate, an actual assignment mechanism and can reasonably infer the distribution of test statistics that could have been realized under alternative treatment assignments. Although we do not know the actual probability distribution of $\mathbf{W}$, following Cattaneo, Frandsen, and Titiunik (2014), we can assume that the probability of being treated for each unit within a certain bandwidth around the threshold is approximately equal to the proportion of the treated within this bandwidth. In practice, we simply set the numbers of the treated $\left(W_{i}=1\right)$ and untreated $\left(W_{i}=0\right)$ in each draw equal to the numbers of the actual treated and untreated.

In addition, due to a large number of possible permutations in our application, we use Monte Carlo approximation to compute $p$-values under randomization inference. That is, a one-sided $p$-value can be approximated as follows:

$$
P \equiv \operatorname{Pr}(T(\mathbf{W}, \mathbf{Y}) \geq \hat{\beta}) \approx \frac{1}{M} \sum_{j=1}^{M} \mathbf{I}\left\{T\left(\mathbf{W}_{j}, \mathbf{Y}\right) \geq \hat{\beta}\right\},
$$

where $\mathbf{W}_{j}$ denotes the $j$ th draw of random treatment assignment based on the assumed assignment mechanism, I is the indicator function that is one if $T\left(\mathbf{W}_{j}, \mathbf{Y}\right) \geq \hat{\beta}$ and otherwise zero, and $M$ is the total number of random draws for the approximation of the distribution. We set $M$ at $10,000 .{ }^{24}$ In the following analysis, we test the sharp null hypothesis of no effect and therefore we use a two-sided $p$-value, that is $2 \times P$.

\subsection{Data}

The data we use are from Japanese Study of Aging and Retirement (JSTAR), which is a longitudinal survey of middle-aged and elderly populations in Japan. Many questions in JSTAR are comparable with those in the Health and Retirement Study (HRS) in the United States and the Survey on Health, Aging and Retirement in Europe (SHARE) in the EU. We use the question on the current utilization of dentures and create a binary variable that takes one if a respondent was using a denture at the time of the survey. By the definition of this outcome

24 The number of simulations is set at 10,000 based on two previous studies, Ho and Imai (2006) and Cattaneo, Frandsen, and Titiunik (2014). Ho and Imai (2006) argue that 10,000 is sufficiently large for a reliable Monte Carlo approximation in their application. 
variable, we consider the extensive margin of denture usage (whether or not a denture is used), in this study. ${ }^{25}$

JSTAR was launched in 2007 by the Research Institute of Economy, Trade and Industry (RIETI) and Hitotsubashi University and has been repeated every two years. We pool all of the data from 2007, 2009 and 2011. To focus on the marginal change of utilization rate at the age of 70 , the elderly population of those aged 65 to 74 is included. In addition, 75 enrollees in Latter-Stage Elderly Healthcare System (LSEHS) are excluded because those who enrolled in LSEHS before age 75 can be people with a disability who are eligible for special subsidies for healthcare utilization provided by local governments. Recipients of public assistance are also excluded.

We cannot, however, exclude those who earn high incomes regardless of the fact that the high-income elderly pay the $30 \%$ coinsurance rate even after their 70th birthday due to a lack of precise registered income information in JSTAR. $\mathrm{RD}$ estimates derived from the whole sample may therefore underestimate the impact of the reduction in the coinsurance rate at age 70 due to the inclusion of these high-income elderly people. The problem of underestimation, however, should not be serious because the share of elderly people in the high-income category can be assumed to be low in our sample, as is suggested in Section 2.3. Even in the worst case, the absolute value of our estimate can be interpreted as a lower bound on a true effect.

Finally, some observations in JSTAR are from the Tohoku region where some respondents might have been affected by the Great Earthquake and Tsunami in March 2011 and subsequently disseminated public medical care assistance. However, we cannot exclude such observations because the security policy of JSTAR prevents us from obtaining residential information for each individual.

Table 2 shows the descriptive statistics of the outcome variables and basic covariates in our sample. The resulting number of observations is 4,047 and the sample consists of data collected in 2007 (33\%), in 2009 (41\%), and 2001 (26\%). $54 \%$ of the individuals observed wear dentures and the average age in months is 838 (69 years and 10 months). The ratio of women is $50 \%$. Education levels are categorized into three strata where $38 \%$ are junior high school graduates or less, $51 \%$ are high school, specialized training school or junior college graduates, and $11 \%$ are university graduates. $83 \%$ of the individuals observed are married and the average number of children is 2.1. See also Appendix A for additional

25 By "extensive" we mean "whether or not he or she wears a denture" By "intensive” we mean "how many artificial teeth he or she has in his or her denture". 
Table 2: Descriptive statistics.

\begin{tabular}{|c|c|c|c|c|c|}
\hline Variable & Obs & Mean & Std. Dev. & Min & Max \\
\hline \multicolumn{6}{|l|}{ Outcome variables } \\
\hline Denture utilization & 4,044 & 0.5401 & 0.4985 & 0 & 1 \\
\hline Chewing ability 1 & 4,044 & 0.5477 & 0.4978 & 0 & 1 \\
\hline Chewing ability 2 & 4,044 & 0.0502 & 0.2184 & 0 & 1 \\
\hline \multicolumn{6}{|c|}{ Assignment variable (not standardized) } \\
\hline Age in months & 4,044 & 838.49 & 34.08 & 780 & 899 \\
\hline \multicolumn{6}{|l|}{ Covariates } \\
\hline Women dummy & 4,044 & 0.5022 & 0.5001 & 0 & 1 \\
\hline \multicolumn{6}{|l|}{ Education level } \\
\hline Low (junior high school or less) & 4,044 & 0.3786 & 0.4851 & 0 & 1 \\
\hline Middle (high school, etc.) & 4,044 & 0.5126 & 0.4999 & 0 & 1 \\
\hline High (university) & 4,044 & 0.1088 & 0.3114 & 0 & 1 \\
\hline Marital status & 4,044 & 0.8314 & 0.3745 & 0 & 1 \\
\hline Number of children & 4,044 & 2.0811 & 0.8987 & 0 & 5 \\
\hline \multicolumn{6}{|l|}{ Year dummy } \\
\hline Year dummy 2007 & 4,044 & 0.3316 & 0.4708 & 0 & 1 \\
\hline Year dummy 2009 & 4,044 & 0.4065 & 0.4912 & 0 & 1 \\
\hline Year dummy 2011 & 4,044 & 0.2619 & 0.4397 & 0 & 1 \\
\hline
\end{tabular}

Notes: When it comes to education level, "Low" means education up to graduation from junior high school or less, "Middle" means graduation from high school, specialized training colleges or junior colleges. "High" means graduation from a university. We have excluded three 2011 observations from our sample because the individuals apparently misreported their ages when compared with their reported ages in 2007 and 2009.

covariates that we will use for preliminary checks and robustness checks. We do not use these covariates in baseline analysis because the inclusion of these covariates further reduces the sample size.

It is also noteworthy that the data collection periods of JSTAR differ by "wave". Data in the first wave (2007) were collected over three months between January 2007 and March 2007, but data in the second wave were collected between January 2009 and December 2009. The period of data collection for the third wave was over one year, running from November 2010 to July 2012. Because of these differences in the data collection periods, the age in month of a respondent, which is an assignment variable for our $\mathrm{RD}$ estimation, does not closely reflect the seasonality of birth timing. This is an important point for the validity of our RD design since the manipulation of the birth timing around school cutoff date, April 2, potentially violates the local randomization assumption around the threshold at the 70th birth month. 
Empirically, Shigeoka (2014b) shows that seasonality of birth timing may reflect unobservable socio-economic characteristics in Japan. ${ }^{26}$ When the data collection period of the survey is in a given month or season, this manipulation becomes a serious threat for age-based RD design. For instance, if data in all of the waves were collected in April, those who had just become 70 years old at the time of the survey would have been born in April. In this case, results from agebased RD may strongly reflect the difference in the unobservable characteristics of respondents before and after the threshold. In fact, Shigeoka (2014a) implements various robustness checks in order to address the potential bias from seasonality of birth timing since his study uses the Patient Survey which is conducted in September every 3 years. ${ }^{27}$ On the other hand, the study design of JSTAR allows us to believe that this seasonality issue is not serious problem to be addressed in our analysis.

\subsection{Preliminary Analysis}

One important assumption for plausible RD designs is that people cannot perfectly manipulate the assignment variable (Lee 2008; Lee and Lemieux 2010). In Appendix B we provide figures showing the density distribution of our sample and present the results of a density test based on McCrary (2008). ${ }^{28}$ Both results indicate that the density of observations doest not change discontinuously at the threshold. This may be partly because age in months at the time of the survey does not reflect respondents' birth month in JSTAR, as is explained previously.

In addition, if the assumption of local randomization around the threshold is plausible, any pre-determined covariates should be continuously distributed around the threshold. This supposition can be tested by checking whether the distributions of observed pre-determined covariates have no discontinuity at the threshold. In Appendix $\mathrm{C}$ we provide bin means of baseline covariates mentioned above and additional covariates listed in Appendix A. This graphical representation shows that there is no discontinuity at the threshold for any pre-determined covariates.

26 Shigeoka (2014b) reveals that birth timing around the school entry cutoff date, April 2, is not random. Rather, he argues that parents manipulate the timing deliberately according to their expectations regarding their child's future achievement given the fact that older children perform better academically than their younger peers (Kawaguchi 2011).

27 To address the seasonality of birth timing, Shigeoka (2014a) controls for birth-month fixed effects, but these controls cannot be incorporated in regression with a short bandwidth such as 6 months.

28 In our density test, we do not calculate an optimal bin size and bandwidth due to the discreteness of our assignment variable, but rather choose a month for our bin size and \pm 60 , \pm 24 , or \pm 12 months for our bandwidth. 
Finally, some may wonder whether there are other healthcare utilizations in JSTAR that show discontinuous changes at the age of 70 in addition to denture utilization. Unfortunately, most questions about healthcare utilization in JSTAR are about utilization status within the last year and therefore not suitable for RD estimation. In Appendix D we plot hospital and dentist visits in the last year against age in months. As expected, all graphs in Figure 8 indicate no discontinuity at the threshold. The graphs also indicate that about $50 \%$ of observed individuals around age 70 visited dentists in the last year. Average dentist visit frequency in the last year for the same age cohorts is around 3 to 5, implying that the average frequency for those who visit dentists at least once is about 6 to 10. This suggests that regular dentist visits are quite common for some individuals observed in the sample.

\section{Results}

\subsection{Graphical Analysis}

Before presenting RD estimates, Figure 1 provides some graphical evidence concerning whether or not there is any jump in the denture utilization rate at the threshold. First, Figure 1(A) with the full sample shows a discontinuous increase in the denture utilization rate at the age of 70 . Second, if we look at subsamples of men and women, there seems to be no jump at the threshold among men (Figure 1(B)) but a clear jump among women (Figure 1(C)). Third, according to Figure 1(D), (E), and (F), there seems to be a discontinuous change at the threshold regardless of education level, although the plots are rather unstable due to the small number of observations in each bin.

\subsection{Effect on Denture Utilization}

\subsubsection{Baseline Estimates}

Table 3 confirms that the intuitive reading of Figure $1(\mathrm{~A})$ is correct: RD estimates are often significantly different from zero regardless of the selection of a bandwidth and a polynomial order and they also do not change considerably when we add predetermined covariates to the regressors. Although estimates vary depending on the combination of the bandwidth and polynomial order, they mostly fall between 0.1 and 0.3 , implying that the $20 \%$ reduction of the coinsurance rate results in around a $10-30 \%$ increase in the denture utilization rate. 


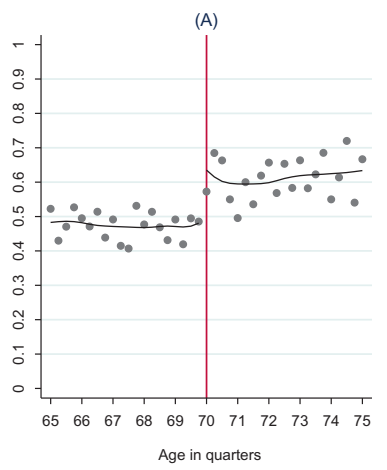

(D)

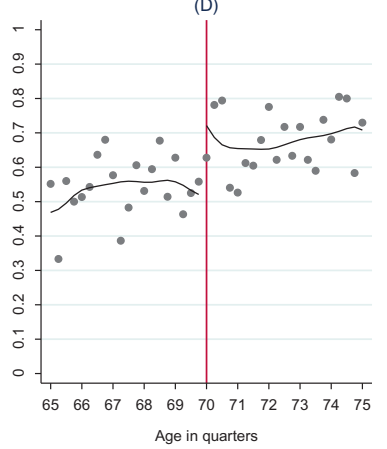

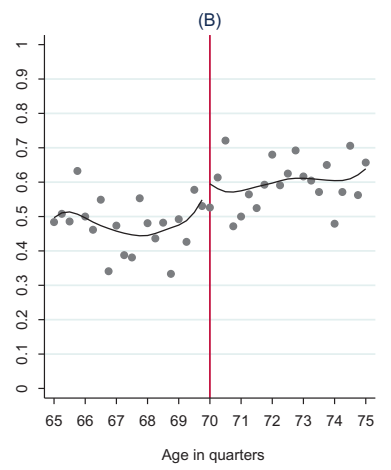

(E)

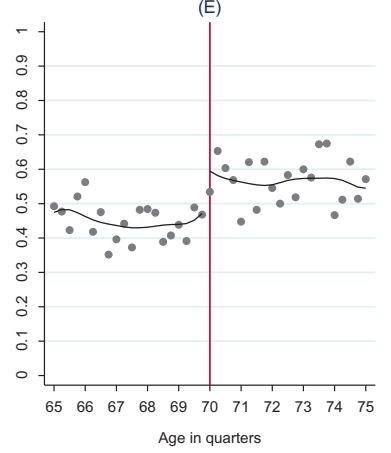

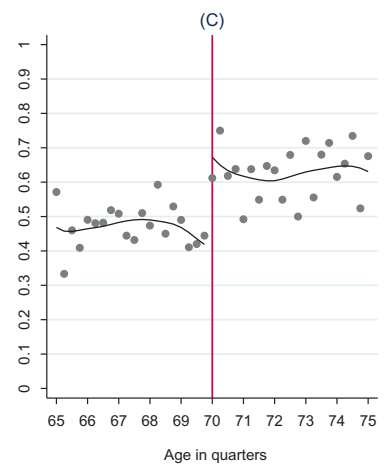

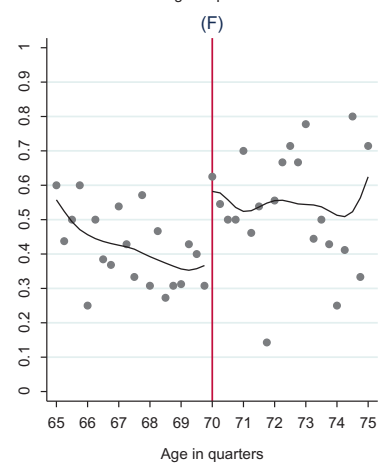

Figure 1: Bin means of the denture utilization rate. (A) All, (B) Men, (C) Women, (D) Low education, (E) Middle education, (F) High education.

Notes: These figures show the means of the probability of wearing dentures at the time of the survey and their smoothers with locally weighted scatterplot smoothing (lowess in Stata 13 is used with a default setting). Age is collapsed into the quarterly term. Figures D, E and F show the subsample results by education level.

The utilization rate averaged across four months just before the age of 70 is approximately $50 \%$, so by a back-of-the-envelope calculation we can conclude that the range of the elasticity of denture utilization with respect to the coinsurance rate is from -0.3 to -0.9 . For our preferred point estimate, we use the point estimate of 0.133 , which is obtained by linear RD estimation with the smallest bandwidth of \pm 6 months and no covariates. ${ }^{29}$ The price elasticity is then

29 As mentioned before, a local linear regression is one of the most common non-parametric methods used in RD designs (Hahn, Todd, and Van der Klaauw 2001; Lee and Lemieux 2010). In addition, we argue that this point estimate is robust for three reasons. First, it is not very different from other linear RD estimates regardless of bandwidth sizes and covariate introduction. Second, it is quite close to RD estimates with higher order polynomials and the largest bandwidth of months. Third, it is also close to most difference-in-means estimates that are discussed in Sections 3.2 and 4.3.2 and presented in Appendix F. 
Table 3: RD estimates for the denture utilization rate (whole sample).

\begin{tabular}{|c|c|c|c|c|}
\hline \multirow{2}{*}{$\begin{array}{l}\text { Polynomial } \\
\text { order }\end{array}$} & \multirow[b]{2}{*}{ \pm 60 months } & \multirow[b]{2}{*}{ \pm 24 months } & \multicolumn{2}{|r|}{ Bandwidth } \\
\hline & & & \pm 12 months & \pm 6 months \\
\hline & & & & No covariates \\
\hline \multirow[t]{3}{*}{ One } & $0.113^{\star \star \star}$ & $0.141^{\star \star \star}$ & $0.157^{\star \star}$ & $0.133^{\star}$ \\
\hline & $(0.028)$ & $(0.042)$ & $(0.056)$ & $(0.061)$ \\
\hline & [5613] & [2423] & [1183] & {$[577.8]$} \\
\hline \multirow[t]{3}{*}{ Two } & $0.114^{\star \star \star}$ & $0.173^{\star \star \star}$ & 0.0730 & $0.188^{\star}$ \\
\hline & $(0.040)$ & $(0.063)$ & $(0.075)$ & $(0.104)$ \\
\hline & [5617] & [2426] & [1185] & [581.6] \\
\hline \multirow[t]{3}{*}{ Three } & $0.153^{\star \star \star}$ & 0.087 & $0.167^{\star}$ & $0.273^{*}$ \\
\hline & $(0.054)$ & $(0.074)$ & $(0.088)$ & $(0.128)$ \\
\hline & [5619] & [2425] & [1188] & [583.1] \\
\hline \multirow[t]{4}{*}{ Four } & $0.168^{\star \star \star}$ & 0.131 & $0.323^{\star \star}$ & 0.241 \\
\hline & $(0.063)$ & $(0.079)$ & $(0.130)$ & $(0.338)$ \\
\hline & [5622] & [2428] & [1191] & {$[583.2]$} \\
\hline & & & & With covariates \\
\hline \multirow{3}{*}{ One } & $0.116^{\star \star \star}$ & $0.152^{\star \star \star}$ & $0.163^{\star \star}$ & $0.126^{\star}$ \\
\hline & $(0.029)$ & $(0.044)$ & $(0.060)$ & $(0.066)$ \\
\hline & [5601] & [2423] & [1193] & 579.3 \\
\hline \multirow[t]{3}{*}{ Two } & $0.121^{\star * \star}$ & $0.181^{\star \star \star}$ & 0.077 & $0.190^{\star}$ \\
\hline & $(0.042)$ & $(0.065)$ & $(0.079)$ & $(0.102)$ \\
\hline & [5604] & [2426] & [1194] & [579.1] \\
\hline \multirow[t]{3}{*}{ Three } & $0.164^{\star \star \star}$ & 0.103 & $0.182^{*}$ & $0.275^{\star \star}$ \\
\hline & $(0.056)$ & $(0.078)$ & $(0.089)$ & $(0.113)$ \\
\hline & [5606] & [2425] & [1197] & [576.3] \\
\hline \multirow[t]{3}{*}{ Four } & $0.185^{\star \star \star}$ & $0.139^{\star}$ & $0.338^{\star \star}$ & 0.402 \\
\hline & $(0.066)$ & $(0.083)$ & $(0.130)$ & $(0.319)$ \\
\hline & [5610] & [2429] & [1200] & [574.3] \\
\hline Sample size & 4,044 & 1,720 & 852 & 414 \\
\hline
\end{tabular}

Notes: ${ }^{\star \star \star},{ }^{\star}$, and ${ }^{\star}$ denote significance at the $1 \%, 5 \%$, and $10 \%$ level respectively. A robust standard error clustered by age in months is presented in parentheses and Akaike Information Criterion (AIC) is provided in square brackets. "Covariates" are the same as those listed in Table 2, but we use dummy variables with respect to the number of children (e. g. a dummy variable that is one in the case of one child) instead of the continuous variable of the number of children.

$(0.133 / 0.485) /(-0.2 / 0.3) \approx-0.41$, where 0.485 is the quarterly mean denture utilization rate just before the age of 70 .

This estimated price elasticity is twice as large as the price elasticity of outpatient care among the Japanese elderly population presented in Shigeoka 
(2014a). However, it should be noted that the implied elasticity is that of the utilization rate of dentures. In other words, we estimate the impact of patient cost sharing at the extensive margin of whether a person wears a denture or not and the extensive margin elasticity of denture utilization cannot necessarily be directly compared to the intensive margin elasticity of outpatient care.

Comparing our results with the RAND HIE, we find a fairly sensitive response to patient cost sharing while the RAND HIE concludes that dental care utilization is sensitive to the introduction of health insurance itself but not very sensitive to the level of patient cost sharing. This inconsistency between results may come from the fact that the studied population and dental care environments in this paper are different from those examined in the RAND HIE.

\subsubsection{Estimates by Gender}

Next, Table 4 shows a surprising contrast in RD estimates between men and women. $\mathrm{RD}$ estimates for men are usually not significantly different from zero, whereas RD estimates for women are mostly statistically significant. RD estimates for women are sometimes unrealistically high, in particular when the combination of a higher order polynomial and a smaller bandwidth, a demanding setting for precise estimation, is used. However RD estimates with a minimum AIC within each bandwidth mostly indicate the estimated effect is around 0.1-0.3 and often larger than 0.2.

The differential response by gender observed in this paper is consistent with Manning and Phelps (1979) who show the price elasticity of dental care among white adults is higher among women than among men, although their study design is not experimental. The observed gender gap is also in line with the findings of the epidemiological literature that indicates women are keener to pursue dental care and dental hygiene (Coda Bertea et al. (2007) and the studies listed therein). ${ }^{30}$

In Table 12 of Appendix E, we further present $\mathrm{RD}$ estimates with additional pre-determined covariates listed in Appendix A. The RD estimates tend to be

30 Using the SHARE dataset of 13 European countries, Listl, Moeller, and Manski (2014) also find that men reported the lack of perceived need as a reason for dental care non-attendance significantly more often than women. One reason we do not find an effect among men may also be related to the fact that according to Section 4.5 the benefit of dentures to the improvement of chewing ability is small or non-existent. If this is the case, men may not gain enough benefit from dentures if they do not care about facial expression and pronunciation and therefore their price elasticity is relatively small. If facial expression and pronunciation do, however, matter to women, their price elasticity may be relatively high even if dentures do not have significant impact on chewing ability. See also the last section of this paper where we discuss this gender gap referring to Glied and Neidell (2010). 
Table 4: RD estimates for the denture utilization rate by gender.

\begin{tabular}{|c|c|c|c|c|c|c|c|c|}
\hline \multirow{3}{*}{$\begin{array}{l}\text { Polynomial } \\
\text { order }\end{array}$} & \multicolumn{8}{|c|}{ Gender and bandwidth } \\
\hline & & & & Men & & & & Women \\
\hline & $\begin{array}{r} \pm 60 \\
\text { months }\end{array}$ & $\begin{array}{r} \pm 24 \\
\text { months }\end{array}$ & $\begin{array}{r} \pm 12 \\
\text { months }\end{array}$ & $\begin{array}{r} \pm 6 \\
\text { months }\end{array}$ & $\begin{array}{r} \pm 60 \\
\text { months }\end{array}$ & $\begin{array}{r} \pm 24 \\
\text { months }\end{array}$ & $\begin{array}{r} \pm 12 \\
\text { months }\end{array}$ & $\begin{array}{r} \pm 6 \\
\text { months }\end{array}$ \\
\hline & & & & & & & \multicolumn{2}{|c|}{ No covariates } \\
\hline One & $\begin{array}{c}0.109^{\star \star} \\
(0.042) \\
{[2824]}\end{array}$ & $\begin{array}{r}0.065 \\
(0.060) \\
{[1232]}\end{array}$ & $\begin{array}{r}0.074 \\
(0.083) \\
{[604]}\end{array}$ & $\begin{array}{r}0.108 \\
(0.093) \\
{[286.2]}\end{array}$ & $\begin{array}{c}0.113^{\star \star \star} \\
(0.038) \\
{[2793]}\end{array}$ & $\begin{array}{c}0.209^{\star * *} \\
(0.055) \\
{[1194]}\end{array}$ & $\begin{array}{l}0.228^{\star \star \star} \\
(0.067) \\
{[586.9]}\end{array}$ & $\begin{array}{r}0.155 \\
(0.104) \\
{[295.2]}\end{array}$ \\
\hline Two & $\begin{array}{r}0.047 \\
(0.058) \\
{[2828]}\end{array}$ & $\begin{array}{r}0.030 \\
(0.087) \\
{[1238]}\end{array}$ & $\begin{array}{r}-0.036 \\
(0.106) \\
{[603]}\end{array}$ & $\begin{array}{r}-0.108 \\
(0.118) \\
{[289]}\end{array}$ & $\begin{array}{l}0.175^{\star \star \star *} \\
(0.051) \\
{[2795]}\end{array}$ & $\begin{array}{l}0.305^{\star \star \star} \\
(0.076) \\
{[1196]}\end{array}$ & $\begin{array}{l}0.1710 \\
(0.120) \\
{[590.4]}\end{array}$ & $\begin{array}{l}0.489^{\star \star \star} \\
(0.118) \\
{[296.4]}\end{array}$ \\
\hline Three & $\begin{array}{r}0.006 \\
(0.075) \\
{[2830]}\end{array}$ & $\begin{array}{r}0.012 \\
(0.100) \\
{[1239]}\end{array}$ & $\begin{array}{r}0.014 \\
(0.145) \\
{[605.6]}\end{array}$ & $\begin{array}{r}0.062 \\
(0.171) \\
{[290.9]}\end{array}$ & $\begin{array}{c}0.284^{\star \star \star} \\
(0.066) \\
{[2795]}\end{array}$ & $\begin{array}{r}0.142 \\
(0.113) \\
{[1196]}\end{array}$ & $\begin{array}{l}0.321^{\star *} \\
(0.145) \\
{[592.3]}\end{array}$ & $\begin{array}{l}0.577^{\star \star \star} \\
(0.141) \\
{[299.2]}\end{array}$ \\
\hline Four & $\begin{array}{r}0.095 \\
(0.092) \\
{[2832]}\end{array}$ & $\begin{array}{r}-0.001 \\
(0.134) \\
{[1242]}\end{array}$ & $\begin{array}{l}-0.004 \\
(0.182) \\
{[609.5]}\end{array}$ & $\begin{array}{l}-0.457 \\
(0.300) \\
{[289.1]}\end{array}$ & $\begin{array}{l}0.234^{\star \star \star} \\
(0.076) \\
{[2798]}\end{array}$ & $\begin{array}{c}0.247^{\star} \\
(0.130) \\
{[1199]}\end{array}$ & $\begin{array}{l}0.676^{\star \star \star *} \\
(0.133) \\
{[592.3]}\end{array}$ & $\begin{array}{l}0.985^{\star \star} \\
(0.386) \\
{[300.9]}\end{array}$ \\
\hline One & $\begin{array}{l}0.112^{\star \star \star} \\
(0.041) \\
{[2823]}\end{array}$ & $\begin{array}{r}0.090 \\
(0.060) \\
{[1235]}\end{array}$ & $\begin{array}{r}0.078 \\
(0.081) \\
{[608.3]}\end{array}$ & $\begin{array}{r}0.121 \\
(0.078) \\
{[288.9]}\end{array}$ & $\begin{array}{l}0.120^{\star \star \star} \\
(0.039) \\
{[2777]}\end{array}$ & $\begin{array}{l}0.228^{\star \star \star} \\
(0.059) \\
{[1186]}\end{array}$ & $\begin{array}{l}\text { With } \\
0.257^{\star \star \star} \\
(0.076) \\
{[591.5]}\end{array}$ & $\begin{array}{c}\text { covariates } \\
0.166 \\
(0.116) \\
{[295.1]}\end{array}$ \\
\hline Two & $\begin{array}{r}0.061 \\
(0.058) \\
{[2824]}\end{array}$ & $\begin{array}{r}0.042 \\
(0.087) \\
{[1237]}\end{array}$ & $\begin{array}{l}-0.049 \\
(0.101) \\
{[607.3]}\end{array}$ & $\begin{array}{l}-0.091 \\
(0.103) \\
{[287.6]}\end{array}$ & $\begin{array}{l}0.188^{\star \star * *} \\
(0.054) \\
{[2778]}\end{array}$ & $\begin{array}{l}0.330^{\star \star * *} \\
(0.081) \\
{[1188]}\end{array}$ & $\begin{array}{r}0.200 \\
(0.127) \\
{[595.1]}\end{array}$ & $\begin{array}{l}0.517^{\star \star * *} \\
(0.146) \\
{[291.7]}\end{array}$ \\
\hline Three & $\begin{array}{r}0.024 \\
(0.075) \\
{[2827]}\end{array}$ & $\begin{array}{r}0.018 \\
(0.098) \\
{[1239]}\end{array}$ & $\begin{array}{r}0.041 \\
(0.141) \\
{[609.8]}\end{array}$ & $\begin{array}{r}0.111 \\
(0.164) \\
{[285.4]}\end{array}$ & $\begin{array}{l}0.304^{\star \star \star} \\
(0.070) \\
{[2778]}\end{array}$ & $\begin{array}{c}0.204^{\star} \\
(0.118) \\
{[1190]}\end{array}$ & $\begin{array}{l}0.362^{\star \star} \\
(0.150) \\
{[597.4]}\end{array}$ & $\begin{array}{l}0.714^{\star \star \star} \\
(0.156) \\
{[290.2]}\end{array}$ \\
\hline Four & $\begin{array}{r}0.112 \\
(0.092) \\
{[2829]}\end{array}$ & $\begin{array}{r}-0.000 \\
(0.127) \\
{[1242]}\end{array}$ & $\begin{array}{l}-0.009 \\
(0.176) \\
{[613.7]}\end{array}$ & $\begin{array}{l}-0.197 \\
(0.367) \\
{[281.3]}\end{array}$ & $\begin{array}{l}0.264^{\star \star \star} \\
(0.082) \\
{[2781]}\end{array}$ & $\begin{array}{c}0.287^{\star *} \\
(0.138) \\
{[1193]}\end{array}$ & $\begin{array}{l}0.701^{\star \star *} \\
(0.149) \\
{[597.7]}\end{array}$ & $\begin{array}{l}1.223^{\star \star} \\
(0.440) \\
{[289.8]}\end{array}$ \\
\hline Sample size & 2,013 & 867 & 424 & 195 & 2,031 & 853 & 428 & 219 \\
\hline
\end{tabular}

Notes: ${ }^{\star \star *},{ }^{\star *}$, and ${ }^{*}$ denote significance at the $1 \%, 5 \%$, and $10 \%$ level respectively. A robust standard error clustered by age in months is presented in parentheses and Akaike Information Criterion (AIC) is provided in square brackets. "Covariates" are the same as those listed in Table 3 but the covariate of gender dummy is dropped.

statistically insignificant when the whole sample is used, possibly due to significantly reduced sample sizes in each estimation. However, our RD estimates examining only the women in our sample are robustly statistically significant even though the sample sizes are often very small. This suggests that the discontinuity of denture utilization at the threshold for women is robustly observed and is not driven by the discontinuous changes of covariates around the threshold. 


\subsubsection{Estimates by Education Level}

Finally, RD estimates for the subgroups with different levels of education are presented in Table 5. Here we provide RD estimates for the sample of women because the significant effect of patient cost sharing is observed only among

Table 5: RD estimates for the denture utilization rate by education level (women).

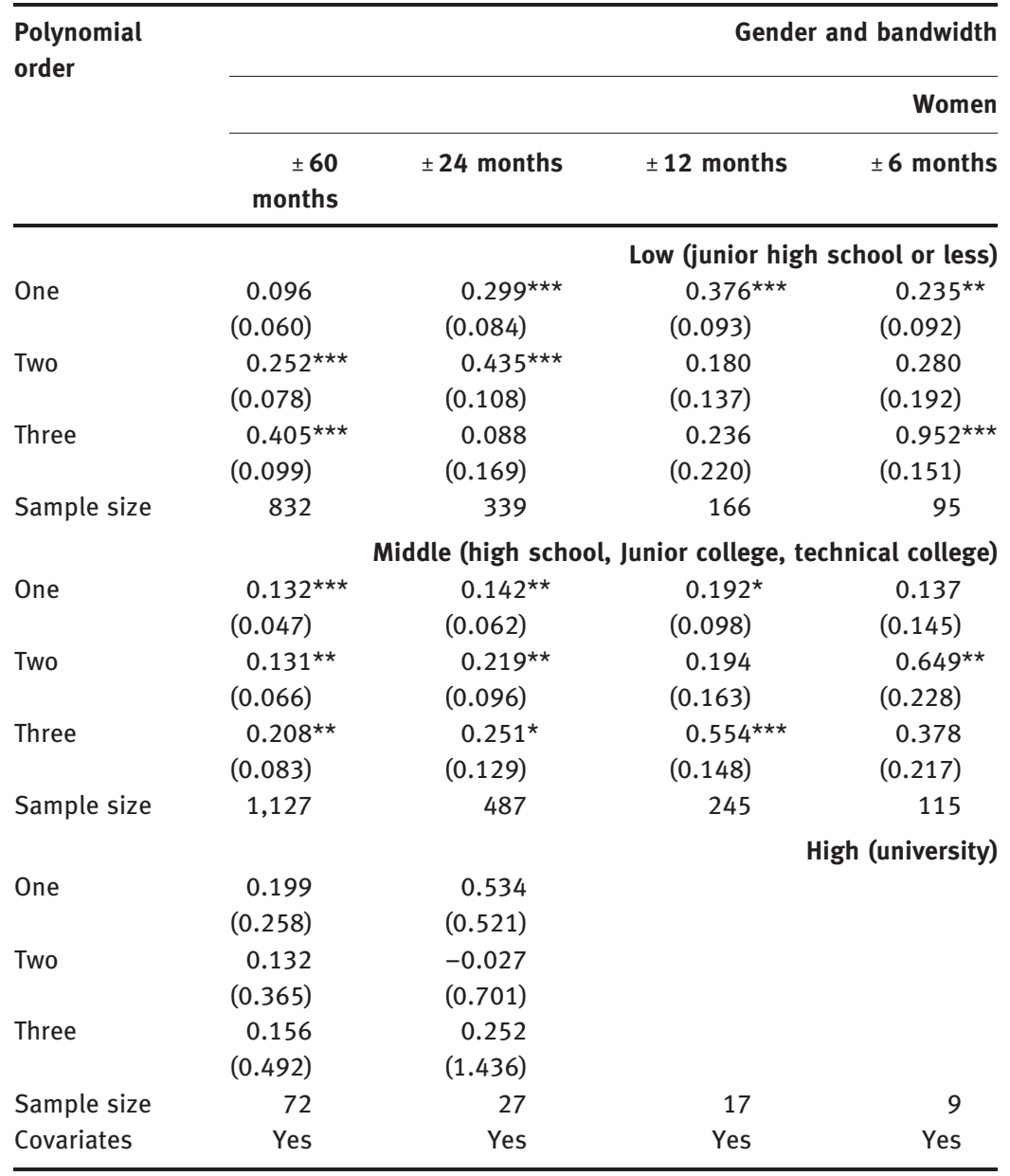

Notes: ${ }^{\star \star \star},{ }^{\star \star}$, and ${ }^{*}$ denote significance at the $1 \%, 5 \%$, and $10 \%$ level respectively. A robust standard error clustered by age in months is presented in parentheses. RD estimates for bandwidths of \pm 12 and \pm 6 months are not provided for highly educated women because the sample sizes are too small. "Covariates" are the same ones as in Table 3 but covariates of education dummies are dropped. 
women in the baseline RD estimation. Estimation results are somewhat unstable and hard to interpret, possibly due to small sample sizes in each estimation. RD estimates, however, are mostly positive and often statistically significant for low and middle education-level women but not significantly different from zero for highly educated women, suggesting that the reduction in the coinsurance rate increases denture utilization among women with low and middle educational attainment but not among highly educated women. It is difficult to confirm this interpretation, however, due to small sample sizes, particularly when it comes to the group of highly educated women. ${ }^{31}$

In Tables 13 and 14 of Appendix E, we provide RD estimates for the subgroups of educational attainment, examining the whole sample (Table 13) and only the men in our sample (Table 14). Overall, Table 13 presents similar results to those in Table 4 with smaller presents similar results to those in Table 4 with smaller estimates and Table 14 suggests that there is no statistically significant effect of patient cost sharing on men across all education levels. Some RD estimates with university degrees are significantly different from zero in both Tables 13 and 14 when larger bandwidths are used, however, suggesting the possibility that highly educated men are more sensitive to the reduction of cost sharing. Unfortunately, it is hard to examine this possible effect heterogeneity due to the small sample size of this subgroup.

\subsection{Donut RD and Randomization Tests}

\subsubsection{Donut RD}

It is possible that some elderly individuals postpone visiting dentists just before reaching the age of 70 in order to receive treatment for dentures with lower out-of-pocket costs after they reach the age at which their burden is reduced. The denture utilization rate would then be lower among individuals nearing their 70th birthday than it would be if there were no discontinuity in the coinsurance rate. This "denture utilization postponement" caused by the intertemporal optimization behavior of the elderly may lead to an upward bias in an RD estimate.

On the other hand, the denture utilization rate might also be lower just after age 70 than the corresponding rate in the case of no discontinuity, because it

31 Another possibility is that highly educated women tend to belong to the high-income group in which the coinsurance rate does not change at age 70 . We cannot reach a decisive conclusion, however, due to a lack of information about precise income levels that determine the coinsurance rate. 
may take some time for the elderly over the age of 70 to visit dentists, ask them to make dentures, and eventually begin wearing dentures. That is, even if a person visits a dentist to begin the process of obtaining a denture on the first day of his or her 70th year, he or she may not actually receive the denture until one or two months later. ${ }^{32}$ This "denture utilization lag" may also cause a bias in an RD estimate. These two sources of bias are explained in Figure 2. In Figure 2, we present the two trend lines, Trend 1 and Trend 2, which represent the trends of denture utilization rates when the coinsurance rates are $30 \%$ and $10 \%$ respectively. In the graph, we assume that both lines have positive trends because more people may wear dentures when they get older, at least until a certain age.

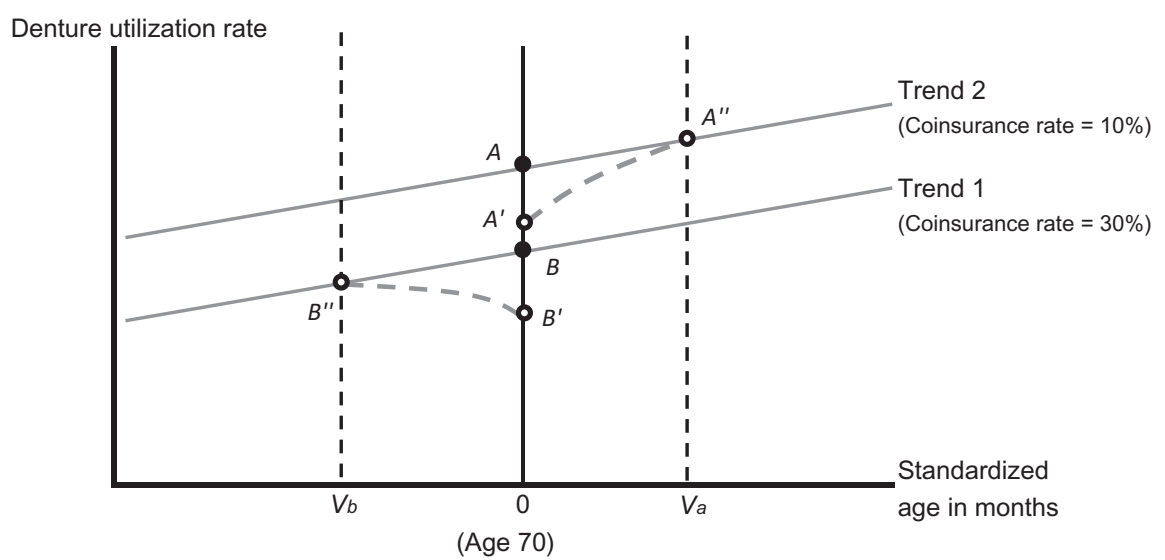

Figure 2: Postponement and lag in denture utilization near the threshold.

What we want to estimate with an RD design is a vertical gap between $\mathrm{A}$ and $\mathrm{B}$ (hereafter the gap $A B$ ), which reflects a difference in denture utilization rate at the age of 70 between individuals with a coinsurance rate of $30 \%$ and those with a rate of $10 \%$. However, if denture utilization postponement exists, the observed denture utilization rate just before the threshold is B', instead of B. That is, some elderly individuals start to postpone getting dentures at a certain time before the threshold ( $V_{b}$ in the graph) and the denture utilization rate

32 According to our own investigation and survey of several dentists and dental clinics, under normal circumstances obtaining a denture takes one or two months from the first consultation with a dentist, and the patient visits the dentist several times during this period. The patient pays a co-payment for the production of his or her dentures, which is the most costly part of the process, at the last visit when he or she receives them. This procedure is presumably similar across Japan under the uniform medical fee scheme of the Japanese public health insurance system. 
diverges from Trend 1. On the other hand, if there is denture utilization lag, then the denture utilization rate just after the threshold is A' instead of A and then converges to Trend 2 at certain point in time ( $V_{a}$ in the graph).

If either or both of these deviations exist for some people, the gap estimated by an RD design is either the gap A'B', AB', or A'B. Graphical investigation with Figure 1 shows that women's denture utilization rate (Figure 1(C)) appears to decrease just before the threshold, implying that an RD estimate may capture the gap AB'. On the other hand, the men's denture utilization rate (Figure 1(B)) does not suggest such deviations around the threshold.

In order to explicitly address these potential biases in RD estimation, we implement the kind of "donut RD” that is proposed by Barreca et al. (2011) to take into account a so-called "heaping" problem and is also utilized in Shigeoka (2014a) to consider a similar problem of potential biases to that of this paper. In donut RD estimation, we drop observations around the threshold and extrapolate their counterfactual distributions without using these possibly noisy observations near the threshold. The donut RD may weaken the idea of local randomization around the threshold, but should serve as a good robustness check.

Ideally, we want to drop observations only between $V_{b}$ and $V_{a}$, where deviations from the trends exist, and then extrapolate the counterfactual distributions between B" and B and between A and A" using observations outside of $V_{b}$ and $V_{a}$. However, because we do not know the true values of $V_{b}$ and $V_{a}$, we have to choose them rather arbitrarily. Finally, for the extrapolation of the counterfactual distributions we can still use the RD estimation model (1).

Results of donut-RD estimates for women are shown in Table 6. Donut-RD estimates are presented with the bandwidth \pm 60 months, \pm 24 months and \pm 12 months where observations around the threshold are dropped from the sample by three criteria: within \pm 1 month, \pm 2 months and \pm 4 months. That is, we assume that $V_{b}$ and $V_{a}$ are either $\pm 1, \pm 2$ or \pm 4 months. Donut-RD estimates with bandwidth \pm 6 months are not shown because in this case the extrapolation of the counterfactual distributions of A-A" and B-B" has to rely on ranges of $V_{i}$ that are too narrow.

Comparison of our RD estimates and donut-RD estimates suggest that there is at least no systematic bias caused by non-random postponement or lag in denture utilization. The range of donut-RD estimates are around 0.1-0.4 in plausible specifications, which are similar to the range of the baseline RD estimates. A counterpart analysis with the whole sample is presented in Table 15 in Appendix $\mathrm{F}$, which also provides similar results.

In the next subsection we will also demonstrate that a difference-in-mean estimate is actually higher when we restrict the sample within the bandwidth of \pm 1 month. According to the donut-RD estimates in Table 6 , however, this fact 


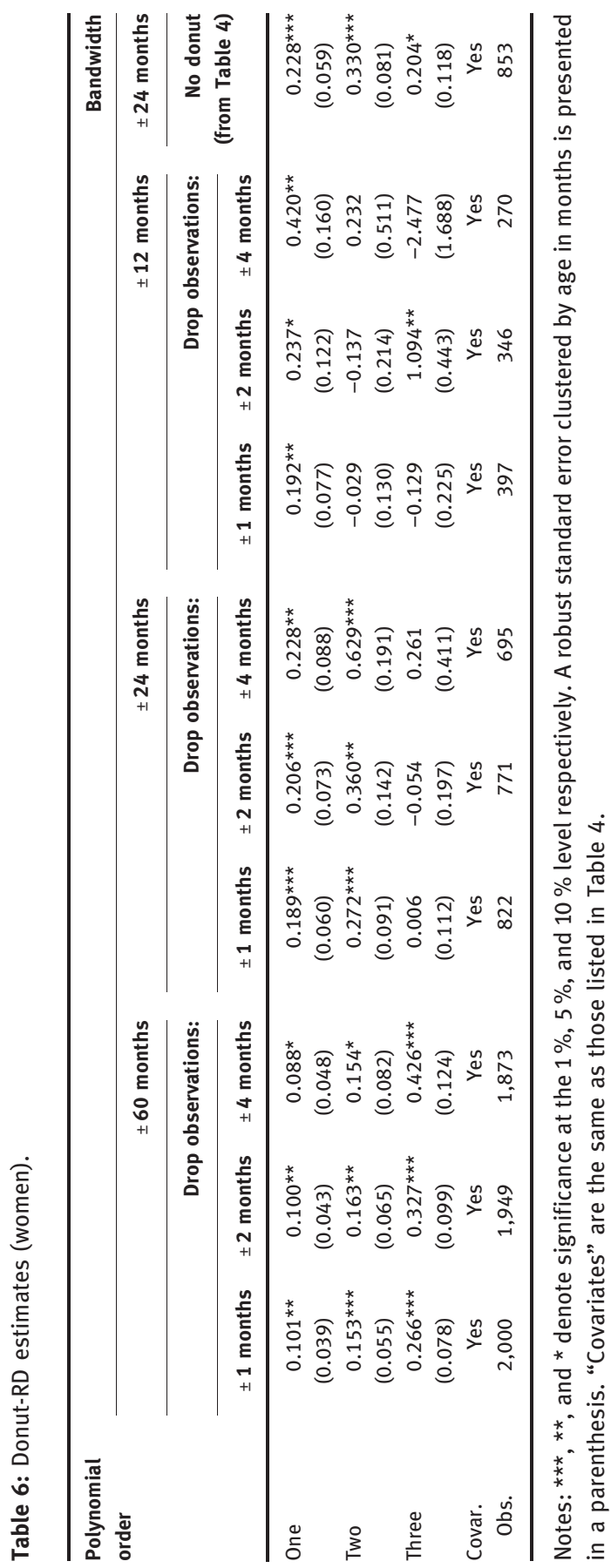


does not lead to serious overestimation of our baseline RD estimates in Table 5 . This may be because a linear RD estimation is not significantly affected by any bump or surge that may exist around the cutoff.

\subsubsection{Randomization Tests}

A randomization test with a difference-in-means estimate using an $\mathrm{RD}$ design requires the assumption of pure local randomization within the chosen bandwidths. Because the assignment variable, age in months, is presumably correlated with the need for dentures, our bandwidths need to be small enough that the age and the need for dentures can be assumed to be unrelated within these time periods. We therefore use the maximum \pm 6 months and the minimum \pm 1 month as bandwidths for the selection of observations.

Table 7 shows the results of randomization tests for the sample of women. First, difference-in-means estimates are always positive and relatively high if the bandwidth of \pm 1 month is used. Second, $p$-values with randomization tests are always below 0.05, implying that the difference-in-means estimates are significantly different from zero in all estimations at the 5\% significance level. These results are consistent with the results of standard RD estimation in Section 4.2. Similar results are obtained when we use the whole sample of men and women, although difference-in-means estimates are smaller (Table 16 in Appendix F).

Table 7: Results of randomization tests (women).

\begin{tabular}{lrrrrrr}
\hline Bandwidth & $\begin{array}{r}\text { Estimate } \\
\text { (Diff. in } \\
\text { means) }\end{array}$ & $\begin{array}{r}p \text {-value } \\
\text { (randomization } \\
\text { test) }\end{array}$ & $\begin{array}{r}p \text {-value } \\
\text { (standard } \\
\text { test) }\end{array}$ & $\begin{array}{r}\text { Sample } \\
\text { size } \\
\text { (total) }\end{array}$ & $\begin{array}{r}\text { Number } \\
\text { of treated }\end{array}$ & $\begin{array}{r}\text { Number of } \\
\text { untreated }\end{array}$ \\
\hline \pm 6 months & 0.2369 & 0.0002 & 0.0004 & 219 & 115 & 104 \\
\pm 5 months & 0.1932 & 0.0026 & 0.0068 & 193 & 104 & 89 \\
\pm 4 months & 0.1951 & 0.0110 & 0.0139 & 158 & 86 & 72 \\
\pm 3 months & 0.1675 & 0.0229 & 0.0671 & 121 & 67 & 54 \\
\pm 2 months & 0.2633 & 0.0044 & 0.0174 & 82 & 46 & 36 \\
\pm 1 month & 0.4790 & 0.0114 & 0.0064 & 31 & 17 & 14 \\
\hline
\end{tabular}

Note: See Section 3.2 about the implementation of randomization tests.

One concern is that the difference-in-means estimates with a bandwidth of \pm 1 month are about twice as large as the other estimates in Table 7 and Table 16 respectively. This suggests that elderly women at the age of 69 and 11 months may postpone going to dentists until they reach the age of 70 and their denture utilization rate is therefore lower due to this postponement behavior. 
Difference-in-means estimates are otherwise around $0.17-0.26$ in Table 7 and about $0.09-0.15$ in Table 16.

\subsubsection{Placebo Randomization Tests}

In order to check the robustness of our results further, we also conduct placebo RD estimation using randomization inference. In these placebo randomization tests, we implement the same randomization tests with a difference-in-means estimate as above, but shift the threshold to a nearby age one month at a time. We would expect that randomization tests using placebo thresholds would yield larger $p$-values than those in actual randomization tests, assuming small $p$-values observed in the above randomization tests are not the consequence of violating the assumption of no correlation between age in months and the demand for dentures within a short bandwidth.

The results shown in Table 8, which again examine the sample of women, demonstrate that our expectation is plausible. $p$-values with randomization tests and the bandwidth of \pm 1 month are smaller than 0.1 only when we use the real threshold of 840 (age 70) or the placebo threshold of 850 (age 70 and 10 months). We do not have a clear explanation of why the randomization-based $p$-value with the placebo threshold of 850 is lower than the others, but it may simply have occurred by chance because we implemented 25 placebo trials with different thresholds. Similar results are obtained by placebo randomization tests with the bandwidth of \pm 2 months. When it comes to the standard test, the $p$-value is less than 0.05 only when the real threshold is used and otherwise always larger than 0.1. See also similar results with the whole sample in Table 17 in Appendix F.

Our placebo trials suggest that it is unlikely that we just accidentally obtain a difference-in-means estimate that is significantly different from zero at the threshold of 840 (age 70). It is also hard to believe that this result is the artifact of positive correlation between age in months and demand for dentures within a bandwidth of \pm 1 month or \pm 2 months because other placebo estimates would be significantly different from zero if this were the case.

\subsection{Difference-in-Differences Strategy}

Exploiting the panel structure of our data, we also implement a simple difference-in-differences (DID) analysis to see whether the same implication is observed with a different empirical strategy. In this analysis, we define the 


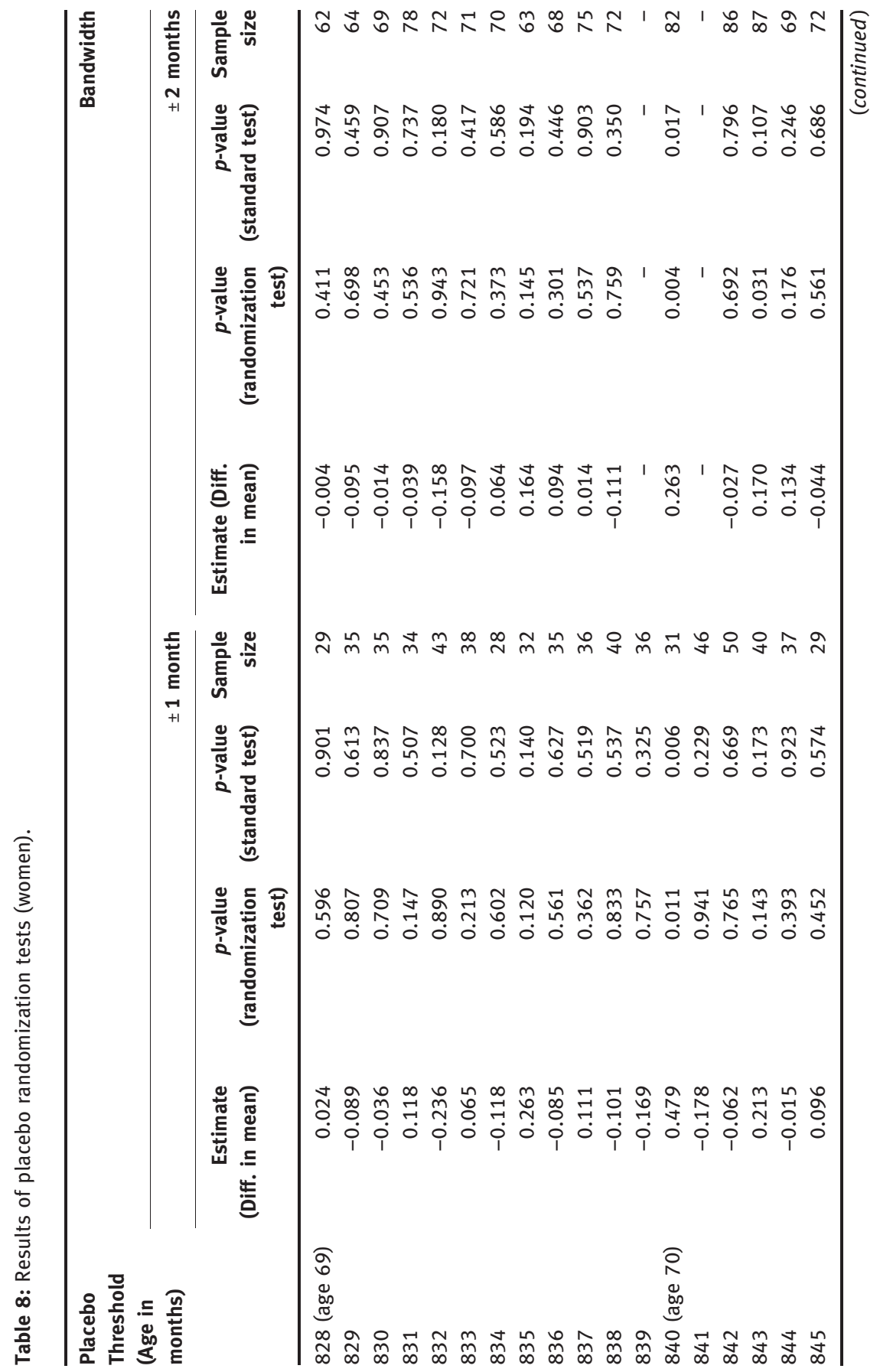




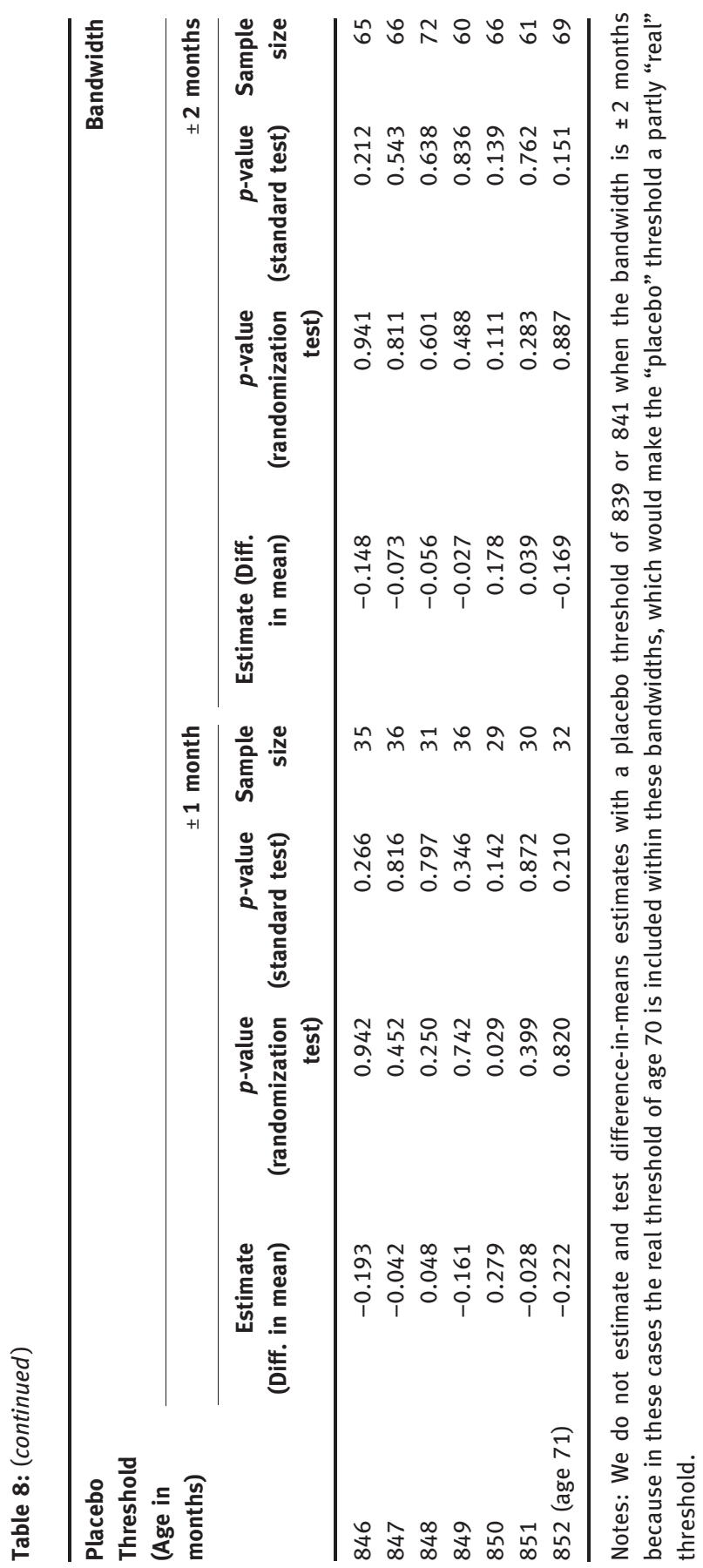


"treatment group" as those who cross the threshold during the sample period. We also use two different control groups: a "younger control group" for those who have not yet crossed the threshold during the sample period (i.e. age 50-69), and an "older control group" for those who have already crossed the threshold before the sample period (i. e. age 70-79).

Our DID model is expressed as follows:

$$
\Delta Y_{i t}=\alpha+\beta_{D I D} \operatorname{Cross} 0_{i t}+\gamma \Delta X_{i t}+u_{i t},
$$

where $\Delta Y_{i t}=Y_{i, t}-Y_{i, t-2}$ and $\Delta X_{i t}=X_{i, t}-X_{i, t-2}$ with $t=2007,2009$, or 2011. $Y_{i t}$ is an indicator variable of denture utilization and $\operatorname{Cross} 70_{i t}$ is an indicator variable that takes one if an observation $i$ crosses the threshold of age 70 between $t$ and $t-2$ and otherwise zero. $X_{i t}$ is the age in months at the survey year $t$ and is meant to control for survey intervals in months between two survey periods. The parameter of interest is $\beta_{D I D}$.

Results are presented in Appendix G. DID estimates using the sample of both men and women are positive and statistically significant, implying that the individuals who cross the age of 70 have a higher tendency to start wearing a denture than individuals in the older and younger control groups. When it comes to DID analysis with the subsamples of men and women, only a DID estimate using the sample of women and the older control group is significantly different from zero (around 0.09). This finding is at least consistent with the finding from our RD design that the effect of cost sharing on denture utilization is observed only for women. Note however that this DID strategy is much cruder than our RD design and therefore we refrain from interpreting $\beta_{D I D}$ as a causal parameter.

\subsection{Effect on Subjective Chewing Ability}

To reveal the costs and benefits of cost sharing for denture utilization, we have to explore both the benefits that the policy brings to patients and increase in healthcare costs. In the case of dentures, the primary objective of wearing dentures is to improve chewing ability. We thus run the same RD regression with the subjective chewing ability as an outcome variable. Fortunately, JSTAR contains a question on chewing ability with a 5-grade self-reported measure, "How solid are the foods you can eat with dentures if you wear them and without dentures if you are not someone who wears dentures?”. In response to this question, respondents are asked to select one of the following five answers: "A1. I can chew and eat everything I want to", "A2. Some things are difficult to chew, but I can eat most foods”, “A3. I can't chew very well, so the foods I can 
eat are restricted”, “A4. I can hardly chew at all” and "A5. I can't chew at all, and consume only liquid foods". We then create a binary variable that takes one if the response is A1 and zero if it is any of the other choices. This variable is to measure the impact of patient cost sharing on unrestricted chewing ability. In addition, to evaluate the impact on restricted chewing ability we also create a binary variable that takes one if the response is either A3, A4, or A5 and otherwise zero.

Graphical representations are provided in Figure 3 and estimation results are summarized in Table 9 for the sample of women. Figure 3 indicates no jump at the threshold for both outcome variables, suggesting that the reduction of cost sharing has no effect on both unrestricted and restricted chewing ability. Table 9 also presents no statistically significant improvement in chewing ability at the threshold regardless of model specification and bandwidth selection. Table 18 in Appendix F shows similar results for the whole sample.

(A)

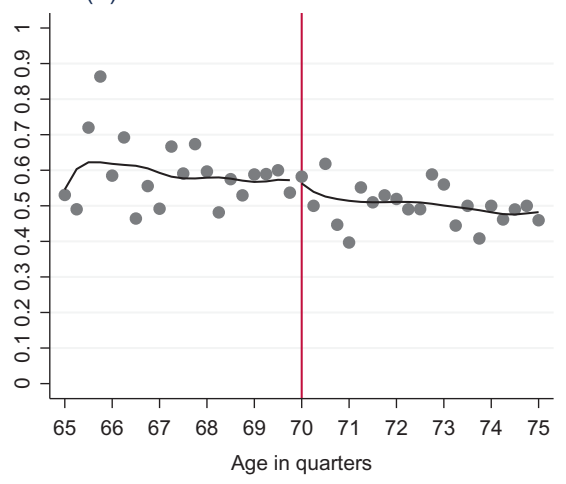

(B)

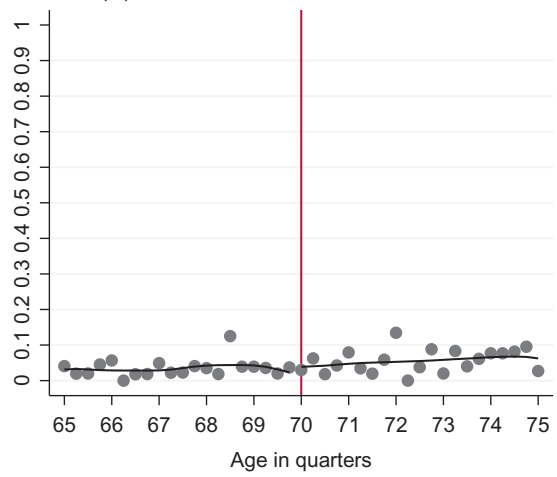

Figure 3: Bin means of the probability in subjective chewing ability (women). (A) Unrestricted chewing ability, (B) Restricted chewing ability.

Notes: These figures show the means of the probability of having unrestricted (or good) chewing ability (figure A) and restricted (or poor) chewing ability (figure B) at the time of the survey and their smoothers with locally weighted scatterplot smoothing (lowess in Stata 13 is used with a default setting). Age is collapsed into quarters The bandwidth of a bin mean is age in quarters.

These results might cast some doubt on the effectiveness of publicly insured dentures for improving the chewing ability of elderly people. However, the reason we do not find a significant impact could also be due to the imprecise measurement of subjective chewing ability in the dataset of JSTAR. For this reason, we have to evaluate the impact on chewing ability with more accurate measures. In addition, an improvement in chewing ability is only part of the expected benefits of wearing dentures. If an improvement in appearance, facial 
Table 9: RD estimates for subjective chewing ability (women).

\begin{tabular}{lcccc}
\hline $\begin{array}{l}\text { Polynomial } \\
\text { order }\end{array}$ & \multicolumn{3}{c}{} & Bandwidth \\
\cline { 2 - 5 } & $\pm \mathbf{6 0}$ months & $\pm \mathbf{2 4}$ months & $\pm \mathbf{1 2}$ months & $\pm \mathbf{6}$ months \\
\hline Unrestricted chewing ability & & & & \\
One & -0.015 & -0.023 & 0.052 & 0.087 \\
& $(0.041)$ & $(0.059)$ & $(0.082)$ & $(0.119)$ \\
Two & -0.005 & -0.001 & -0.005 & -0.244 \\
& $(0.055)$ & $(0.081)$ & $(0.097)$ & $(0.147)$ \\
Three & -0.047 & 0.068 & 0.026 & -0.046 \\
& $(0.070)$ & $(0.110)$ & $(0.145)$ & $(0.160)$ \\
Restricted chewing ability & & & & \\
One & -0.005 & 0.007 & 0.017 & 0.029 \\
& $(0.017)$ & $(0.025)$ & $(0.030)$ & $(0.032)$ \\
Two & 0.005 & 0.028 & 0.016 & 0.009 \\
& $(0.024)$ & $(0.036)$ & $(0.040)$ & $(0.068)$ \\
Three & 0.015 & 0.011 & 0.045 & 0.097 \\
& $(0.031)$ & $(0.040)$ & $(0.047)$ & $(0.069)$ \\
Covariates & $Y e s$ & Yes & Yes & Yes \\
sample size & 2,031 & 853 & 428 & 219 \\
\hline
\end{tabular}

Notes: ${ }^{* \star *},{ }^{* \star}$, and * denote significance at the $1 \%, 5 \%$, and $10 \%$ level respectively. A robust standard error clustered by age in months is presented in parentheses. "Covariates" are the same as in Table 3.

expression or pronunciation due to newly attached dentures is of great importance to the individual's psychological well-being, it may compensate for the increased healthcare costs brought on by the jump in the utilization rate even without any substantial improvement in chewing ability.

\section{Concluding Remarks}

Despite the recent accumulation of studies on the impact of health insurance coverage on healthcare utilization and health, the effects of patient cost sharing on medical and dental utilization and outcomes have not been sufficiently studied. This paper examined how the denture utilization among the Japanese elderly population responds to cost sharing, employing a regression discontinuity design that exploited a sharp reduction of the coinsurance rate from $30 \%$ to $10 \%$ at the age of 70 years. Given that the two important health insurance experiments (RAND HIE and Oregon HIE) did not cover dental care for the elderly, these results from a quasiexperiment on denture usage, which is the most common dental treatment utilized by the elderly, are of particular importance. 
The estimated extensive margin elasticity of denture utilization is approximately -0.41 , which is twice as large as that presented in Shigeoka (2014a) who examined the intensive margin elasticity of outpatient healthcare utilization in Japan with an experimental design similar to ours, suggesting the demand for dentures is more sensitive to cost sharing than other outpatient healthcare services. In addition, we find that the sensitivity to cost sharing varies across individual characteristics, showing a significant increase in denture usage only among women.

Despite the dramatic increase in denture usage just after an individual's 70th birthday as a whole, however, we find no improvement in subjective chewing ability, which is one of the main objectives of wearing dentures. Indeed, the selfreported measure of chewing ability is completely smooth around age 70, without any discontinuous changes. It may be that no improvement in subjective chewing ability is observed because the elderly individuals who decide to purchase dentures just after reaching the age of 70 tend to wear dentures to improve facial expression and pronunciation, rather than to improve chewing ability.

The finding that women respond to the reduction in cost-sharing for dentures in spite of obtaining no improvement in subjective chewing ability may suggest that aesthetic factors are important in their deciding to utilize dentures, at least on the margin. For example, Glied and Neidell (2010)'s findings suggest that women with poor oral health may suffer from consumer and employer discrimination that is not observed among men. Although their study focuses on labor market outcomes of poor oral health, this sort of gender-specific discrimination or preference regarding oral health may also exist in non-labor market environments. If this is the case, women's denture utilization may respond to reduced cost-sharing even without any improvement in chewing ability because they expect large aesthetic benefits from wearing dentures. On the other hand, men are not likely to make new dentures as a result of reduced cost-sharing because the main benefit of dentures for men is probably the improvement of chewing ability, on which we find no marginal effects of reduced cost-sharing. The gender-specific effect that we found may also reflect such gender-related social and individual preferences about oral health.

Ultimately, if we believe that the only social benefit from dentures is chewing ability, and that subjectively measured chewing ability in JSTAR correctly reflects actual chewing ability, then the social cost of reduced cost sharing for dentures at age 70 may exceed its social benefit because little benefit is observed while the cost increases. However, we should also emphasize that the sensitivity to patient cost sharing is substantially heterogeneous and the improvement of chewing ability is not the sole objective of wearing dentures. More systematic evaluations of chewing ability and other outcomes are required in future studies. 
Acknowledgements: We acknowledge the use of data from the Research Institute of Economy, Trade and Industry (RIETI) in the Ministry of Economy, Trade and Industry in Japan. We also thank RIETI for generously providing the information on age in months of each observation that was not included in the original data. We are grateful to the two anonymous references, Satoshi Abe, Matz Dahlberg, Hideki Hashimoto, Toshiaki Iizuka, Che-Yuan Liang, Yuya Mizuno, Eva Mörk, David Neumark, Toshihiro Tamaki, Janne Tukiainen, and seminar participants at Uppsala, Niigata and Milan for useful comments. The views expressed in this paper do not reflect those of National Institute of Population and Social Security Research or the Institute of Health Economics and Policy. All errors are our own.

\section{Appendix A: Descriptive Statistics of Additional Covariates}

Table 10: Descriptive statistics of additional covariates.

\begin{tabular}{lrrrrr}
\hline Variable & Obs & Mean & Std. Dev. & Min & Max \\
\hline Binary variables & & & & & \\
Health insurance: National association & 3,395 & 0.1317 & 0.3382 & 0 & 1 \\
Health insurance: Corporation & 3,395 & 0.0480 & 0.2138 & 0 & 1 \\
Health insurance: Municipality & 3,395 & 0.8065 & 0.3951 & 0 & 1 \\
Health insurance: Cooperative & 3,395 & 0.0138 & 0.1169 & 0 & 1 \\
Smoking & 3,705 & 0.1425 & 0.3496 & 0 & 1 \\
Working & 4,029 & 0.3495 & 0.4769 & 0 & 1 \\
Glasses and contact lenses & 3,654 & 0.6965 & 0.4598 & 0 & 1 \\
Hearing aids & 4,022 & 0.0321 & 0.1762 & 0 & 1 \\
Faecal Occult Blood Test (past two years) & 4,001 & 0.4616 & 0.4986 & 0 & 1 \\
Health checkup (past one year) & 4,001 & 0.6091 & 0.4880 & 0 & 1 \\
Working (spouse) & 3,301 & 0.3193 & 0.4663 & 0 & 1 \\
Live with own income (past one year) & 3,960 & 0.9035 & 0.2953 & 0 & 1 \\
Financial support for others (past one year) & 3,960 & 0.0601 & 0.2377 & 0 & 1 \\
Own a car/cars & 3,960 & 0.7578 & 0.4285 & 0 & 1 \\
Own estates other than residence & 3,903 & 0.2977 & 0.4573 & 0 & 1 \\
Manager / Executive & 3,902 & 0.1181 & 0.3228 & 0 & 1 \\
Receive inheritance (past one year) & 3,672 & 0.1988 & 0.3992 & 0 & 1 \\
Continuous variables & & & & & \\
Body mass index (BMI) & 3,967 & 23.26 & 3.15 & 14.01 & 64.92 \\
Disposable income (10,000 yen, yearly) & 2,428 & 204.35 & 158.32 & 0 & 900 \\
Cost of food (Yen, monthly) & 2,740 & 63,890 & 31,571 & 0 & 150,000 \\
Cost of living (Yen, monthly) & 2,739 & 167,177 & 85,949 & 0 & 400,000 \\
\hline & & & & &
\end{tabular}




\section{Appendix B: Smoothness of the Density of the Assignment Variable}
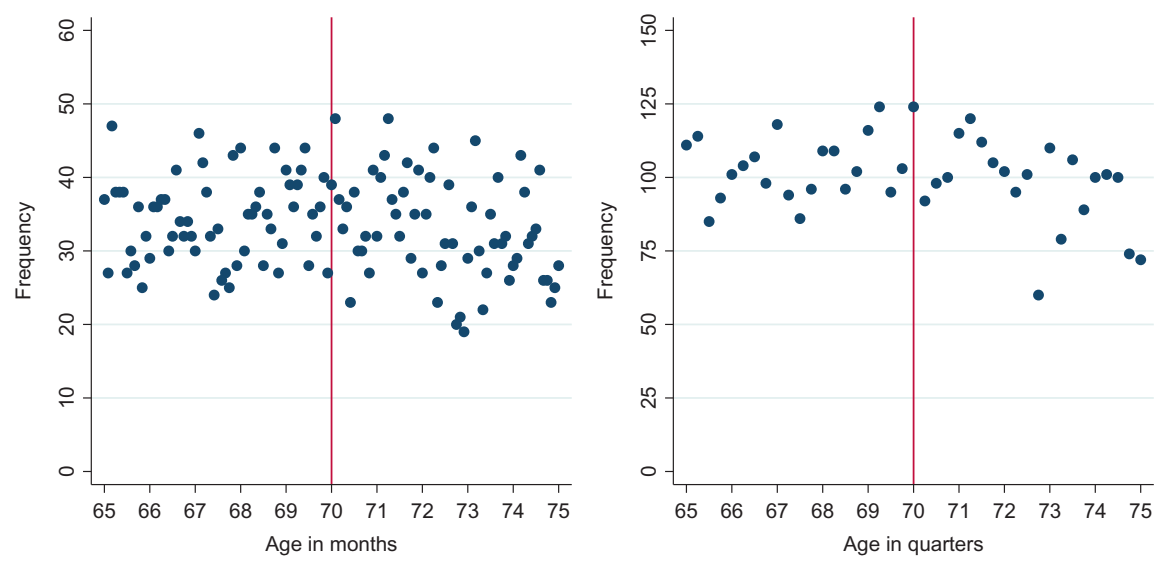

Figure 4: Density of observations.

Table 11: McCrary (2008)'s test.

\begin{tabular}{lrrr}
\hline Polynomial order & \multicolumn{3}{c}{ Bandwidth } \\
\cline { 2 - 4 } & $\mathbf{\pm 6 0}$ months & $\mathbf{2 4}$ months & $\mathbf{\pm 1 2 \text { months }}$ \\
\hline One & 1.528 & 0.125 & 7.094 \\
& $(2.303)$ & $(3.416)$ & $(4.662)$ \\
\multirow{2}{*}{ Two } & 786.4 & 310.6 & 155.1 \\
& 0.605 & 3.816 & $13.790^{\star}$ \\
\multirow{2}{*}{ Three } & $(3.481)$ & $(5.214)$ & $(6.823)$ \\
& 789.9 & 313.3 & 153.9 \\
& 2.558 & $15.462^{\star \star}$ & 12.883 \\
Sample size & $(4.687)$ & $(6.674)$ & $(10.344)$ \\
& 793.2 & 308.8 & 156.9 \\
\end{tabular}

Notes: ${ }^{* \star},{ }^{\star \star}$, and $*$ denote significance at the $1 \%, 5 \%$, and $10 \%$ level respectively. 


\section{Appendix C: Smoothness of Pre-Determined Covariates}

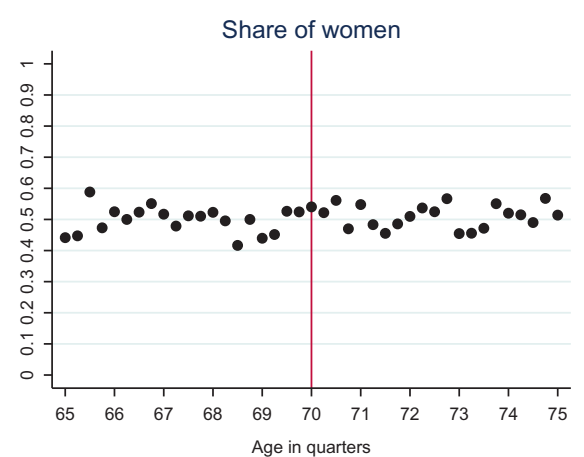

Education level

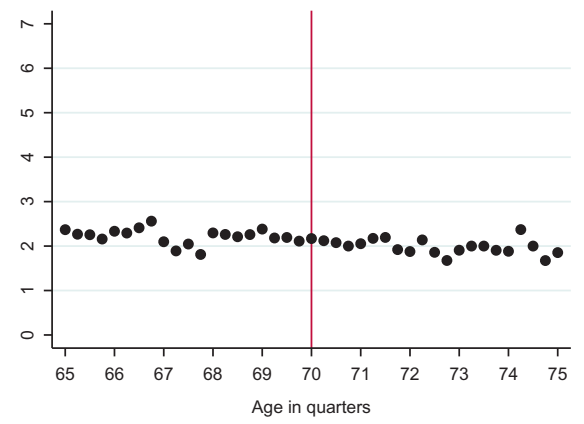

Figure 5: Bin means of baseline covariates.

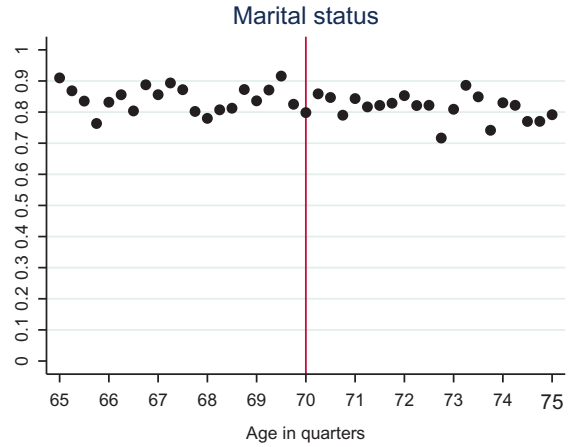

Number of children

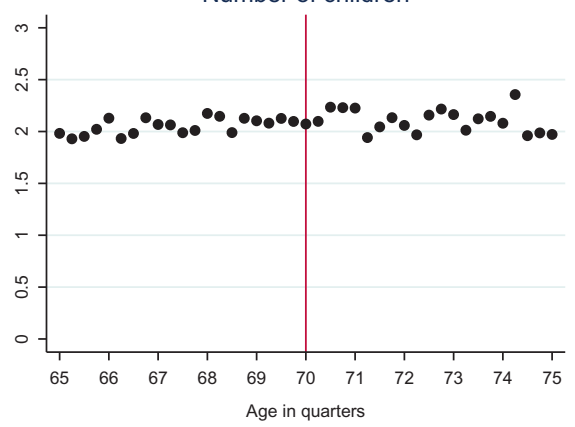



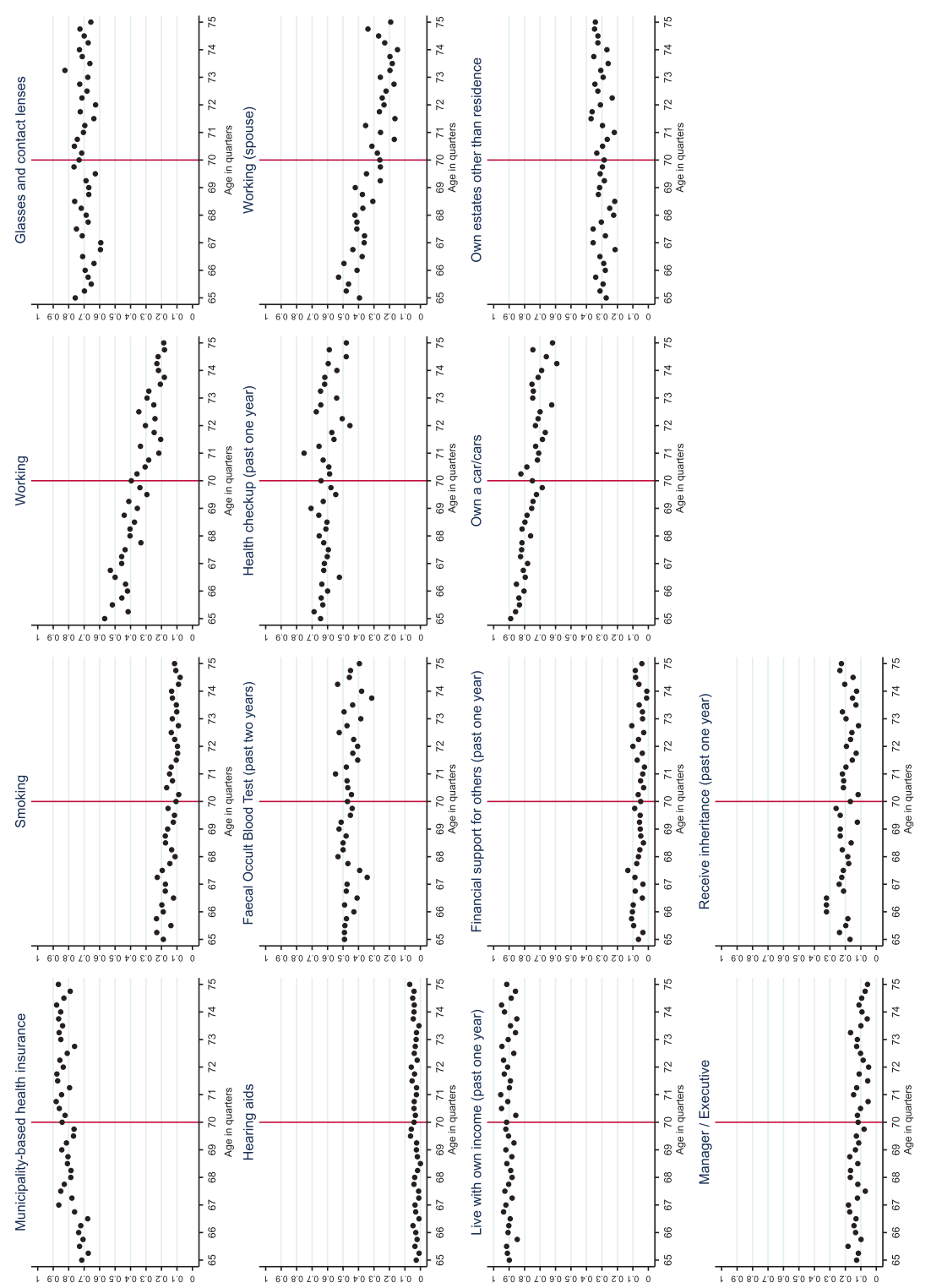

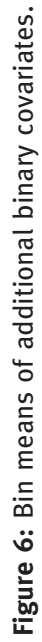



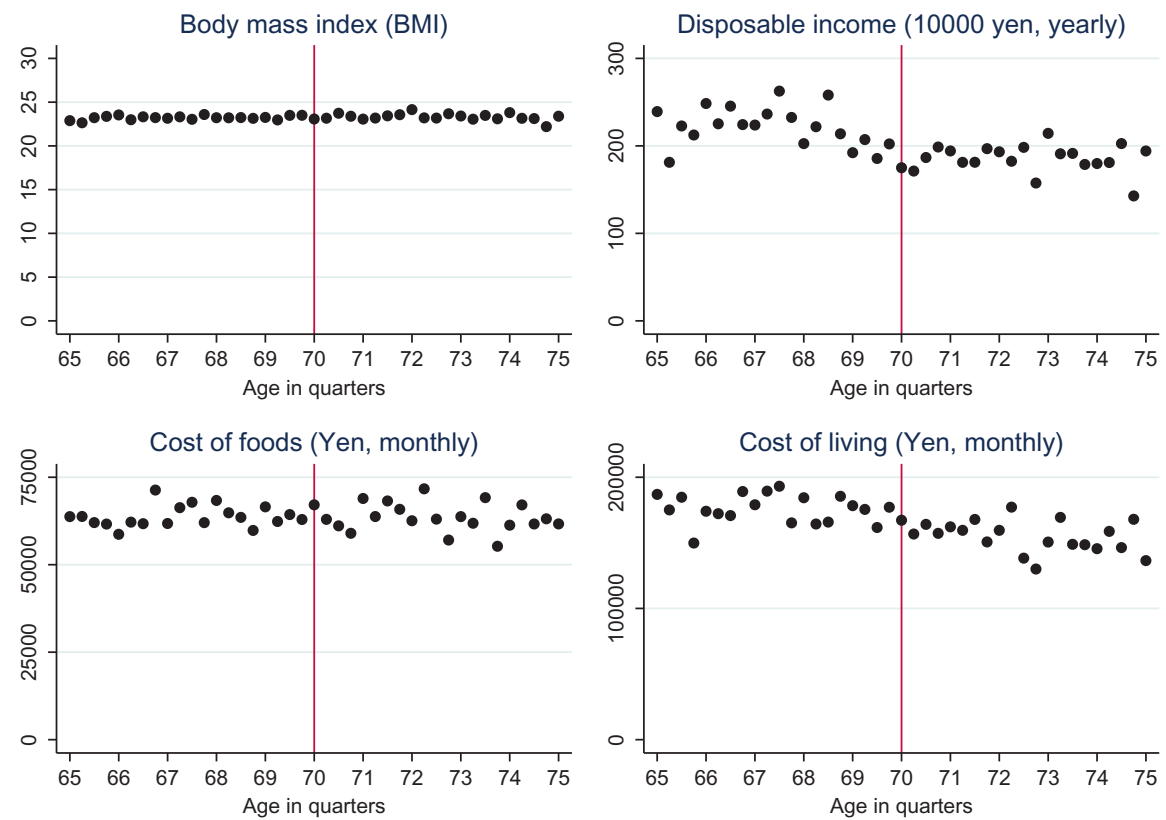

Figure 7: Bin means of additional continuous covariates. 


\section{Appendix D: Hospital and Dental Visits}
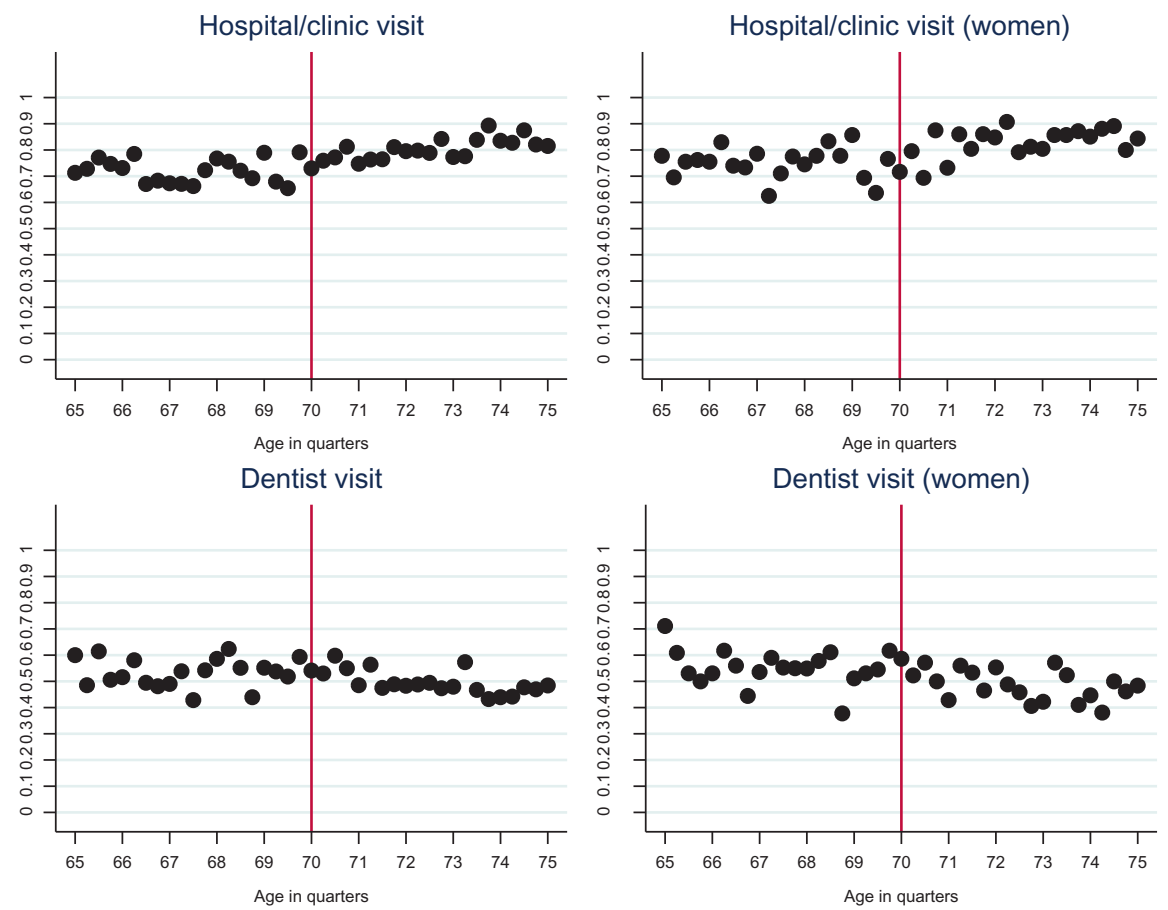

Dentist visit frequency

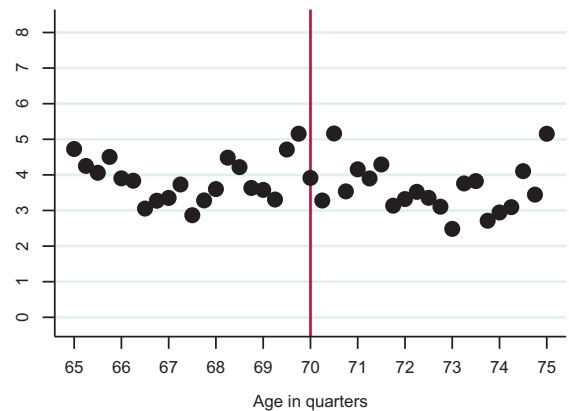

Dentist visit frequency (women)

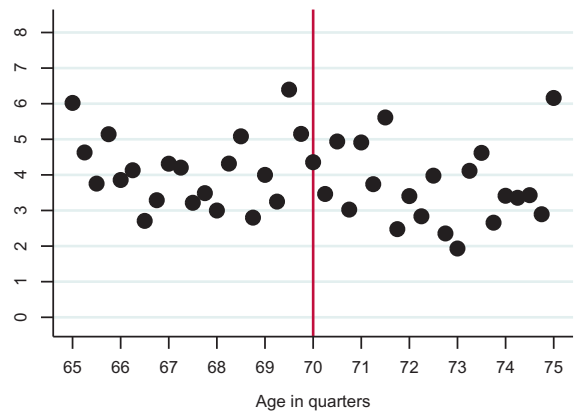

Figure 8: Bin means of hospital and dentist visits within the last year.

Notes: "Hospital/clinic visit" or "dentist visit" is a binary variables that indicates whether a respondent went to a hospital/clinic or a dentist in the last year. "Dentist visit frequency" represents the number of dentist visits in the last year. 


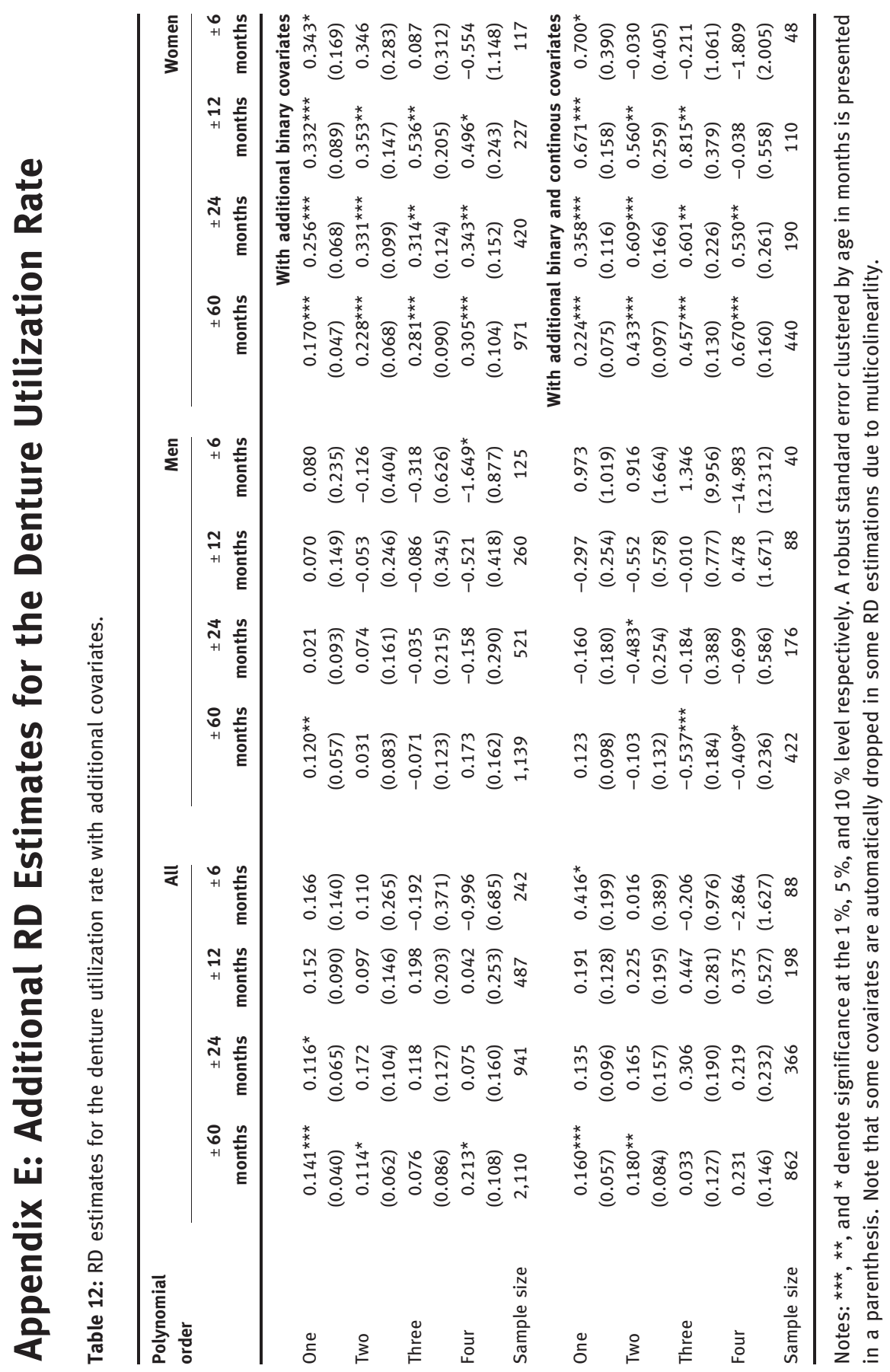


Table 13: RD estimates for the denture utilization rate by education level (whole sample).

\begin{tabular}{|c|c|c|c|c|}
\hline \multirow{3}{*}{$\begin{array}{l}\text { Polynomial } \\
\text { order }\end{array}$} & \multicolumn{4}{|c|}{ Gender and bandwidth } \\
\hline & \multirow[b]{2}{*}{ \pm 60 months } & \multirow[b]{2}{*}{ \pm 24 months } & \multicolumn{2}{|c|}{ Men and Women } \\
\hline & & & \pm 12 months & \pm 6 months \\
\hline & & & \multicolumn{2}{|c|}{ Low (junior high school or less) } \\
\hline \multirow[t]{2}{*}{ One } & 0.058 & $0.159 * \star$ & $0.260 * \star \star$ & $0.185^{\star \star}$ \\
\hline & $(0.047)$ & $(0.059)$ & $(0.070)$ & $(0.060)$ \\
\hline \multirow[t]{2}{*}{ Two } & $0.148^{\star \star}$ & $0.299 * \star \star$ & 0.038 & -0.126 \\
\hline & $(0.059)$ & $(0.082)$ & $(0.059)$ & $(0.131)$ \\
\hline \multirow[t]{2}{*}{ Three } & $0.199 * \star \star$ & 0.089 & 0.061 & $0.287^{\star *}$ \\
\hline & $(0.067)$ & $(0.061)$ & $(0.120)$ & $(0.124)$ \\
\hline \multirow[t]{2}{*}{ Sample size } & 1,531 & 631 & 313 & 158 \\
\hline & \multicolumn{4}{|c|}{ Middle (high school, Junior college, technical college) } \\
\hline \multirow[t]{2}{*}{ One } & $0.126^{\star * \star}$ & $0.119^{*}$ & 0.084 & 0.052 \\
\hline & $(0.041)$ & $(0.067)$ & $(0.092)$ & $(0.112)$ \\
\hline \multirow[t]{2}{*}{ Two } & 0.082 & 0.078 & 0.014 & 0.389 ** \\
\hline & $(0.063)$ & $(0.102)$ & $(0.141)$ & $(0.156)$ \\
\hline \multirow[t]{2}{*}{ Three } & 0.107 & 0.055 & $0.306^{\star \star}$ & 0.204 \\
\hline & $(0.086)$ & $(0.123)$ & $(0.130)$ & $(0.202)$ \\
\hline \multirow[t]{2}{*}{ Sample size } & 2,073 & 904 & 449 & 214 \\
\hline & & & & (university) \\
\hline \multirow[t]{2}{*}{ One } & $0.267^{\star \star \star}$ & $0.339^{\star \star \star}$ & 0.300 & $0.508^{*}$ \\
\hline & $(0.077)$ & $(0.119)$ & $(0.187)$ & $(0.275)$ \\
\hline \multirow[t]{2}{*}{ Two } & $0.231^{\star *}$ & 0.235 & 0.544 & 0.200 \\
\hline & $(0.113)$ & (0.199) & $(0.345)$ & $(0.213)$ \\
\hline \multirow[t]{2}{*}{ Three } & $0.307^{\star}$ & 0.318 & 0.127 & -0.379 \\
\hline & $(0.158)$ & $(0.254)$ & $(0.272)$ & $(0.493)$ \\
\hline Sample size & 440 & 185 & 90 & 42 \\
\hline Covariates & Yes & Yes & Yes & Yes \\
\hline
\end{tabular}

Notes: ${ }^{\star \star \star},{ }^{\star \star}$, and * denote significance at the $1 \%, 5 \%$, and $10 \%$ level respectively. A robust standard error clustered by age in months is presented in parentheses. 
Table 14: RD estimates for the denture utilization rate by education level (men).

\begin{tabular}{|c|c|c|c|c|}
\hline \multirow{3}{*}{$\begin{array}{l}\text { Polynomial } \\
\text { order }\end{array}$} & \multicolumn{4}{|c|}{ Gender and bandwidth } \\
\hline & \multirow[b]{2}{*}{ \pm 60 months } & & \multicolumn{2}{|r|}{ Men } \\
\hline & & \pm 24 months & \pm 12 months & \pm 6 months \\
\hline & & & \multicolumn{2}{|c|}{ Low (junior high school or less) } \\
\hline \multirow[t]{2}{*}{ One } & 0.011 & -0.028 & 0.113 & 0.096 \\
\hline & $(0.075)$ & $(0.109)$ & $(0.146)$ & $(0.231)$ \\
\hline \multirow[t]{2}{*}{ Two } & 0.027 & 0.095 & -0.134 & $-0.675^{\star \star}$ \\
\hline & $(0.105)$ & $(0.177)$ & $(0.165)$ & $(0.226)$ \\
\hline \multirow[t]{2}{*}{ Three } & -0.095 & 0.002 & -0.019 & -0.354 \\
\hline & $(0.135)$ & $(0.209)$ & $(0.374)$ & $(0.414)$ \\
\hline \multirow[t]{2}{*}{ Sample size } & 699 & 292 & 147 & 63 \\
\hline & \multicolumn{4}{|c|}{ Middle (high school, Junior college, technical college) } \\
\hline \multirow[t]{2}{*}{ One } & $0.119^{\star}$ & 0.086 & -0.017 & -0.025 \\
\hline & $(0.060)$ & $(0.095)$ & $(0.117)$ & $(0.103)$ \\
\hline \multirow[t]{2}{*}{ Two } & 0.037 & -0.086 & -0.165 & 0.140 \\
\hline & $(0.087)$ & $(0.134)$ & $(0.133)$ & $(0.134)$ \\
\hline \multirow[t]{2}{*}{ Three } & -0.006 & -0.124 & 0.048 & 0.436 \\
\hline & $(0.115)$ & $(0.133)$ & $(0.141)$ & $(0.244)$ \\
\hline \multirow[t]{2}{*}{ Sample size } & 946 & 417 & 204 & 99 \\
\hline & & & \multicolumn{2}{|c|}{ High (university) } \\
\hline \multirow[t]{2}{*}{ One } & $0.267^{\star \star \star}$ & $0.312^{\star \star}$ & 0.263 & 0.528 \\
\hline & $(0.086)$ & $(0.122)$ & $(0.171)$ & $(0.307)$ \\
\hline \multirow[t]{2}{*}{ Two } & $0.216^{\star}$ & 0.223 & 0.414 & -0.063 \\
\hline & $(0.125)$ & $(0.202)$ & $(0.259)$ & $(0.204)$ \\
\hline \multirow[t]{2}{*}{ Three } & $0.313^{\star}$ & $0.339^{*}$ & 0.255 & -0.004 \\
\hline & $(0.161)$ & $(0.193)$ & $(0.243)$ & $(0.638)$ \\
\hline Sample size & 368 & 158 & 73 & 33 \\
\hline Covariates & Yes & Yes & Yes & Yes \\
\hline
\end{tabular}

Notes: ${ }^{\star \star \star}$, ${ }^{\star \star}$, and * denote significance at the $1 \%, 5 \%$, and $10 \%$ level respectively. A robust standard error clustered by age in months is presented in parentheses. 


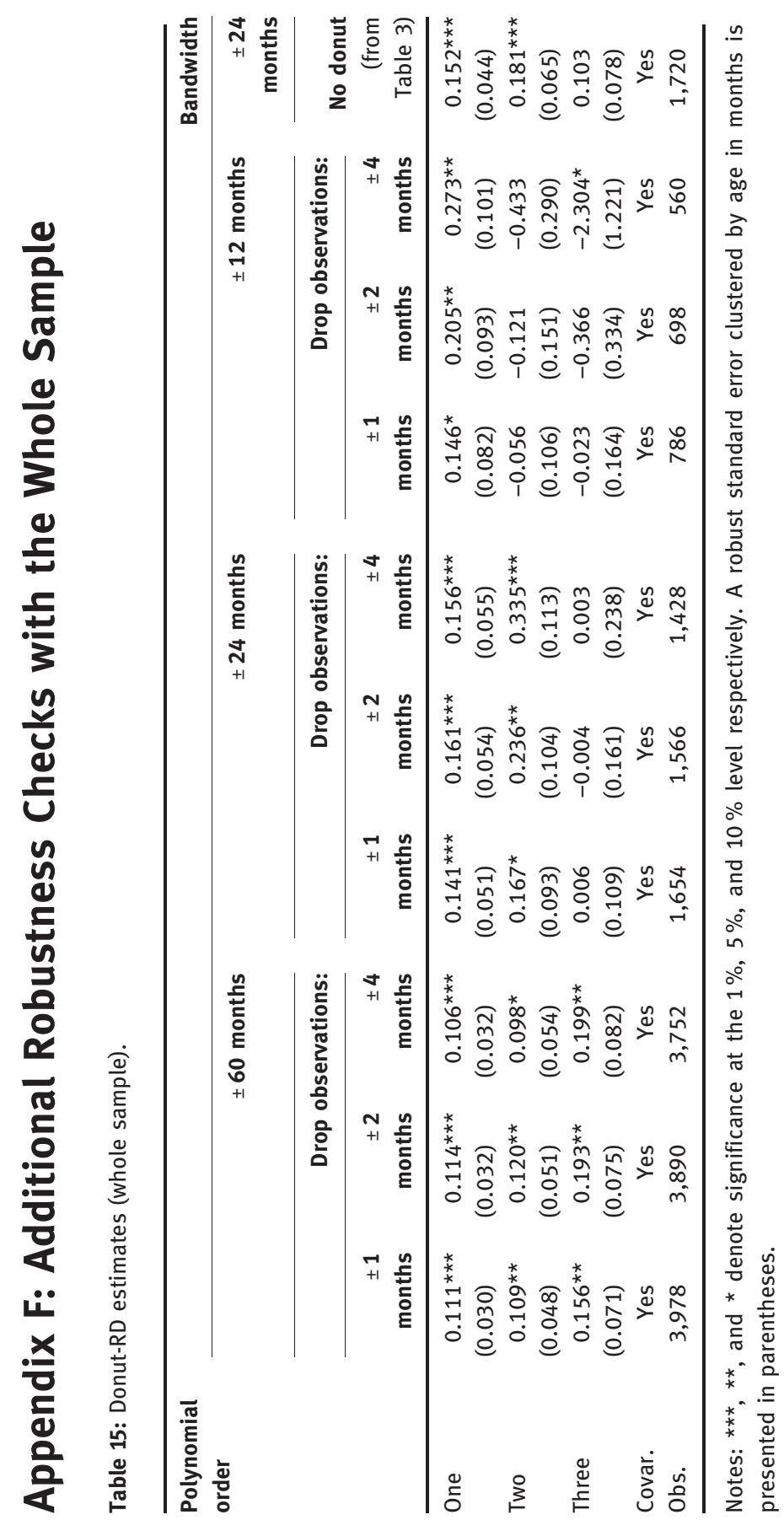


Table 16: Results of randomization tests (whole sample).

\begin{tabular}{lrrrrrr}
\hline Bandwidth & $\begin{array}{r}\text { Estimate } \\
\text { (Diff. in } \\
\text { means) }\end{array}$ & $\begin{array}{r}\boldsymbol{p} \text {-value } \\
\text { (randomization } \\
\text { test) }\end{array}$ & $\begin{array}{r}\boldsymbol{p} \text {-value } \\
\text { (standard } \\
\text { test) }\end{array}$ & $\begin{array}{r}\text { Sample } \\
\text { size } \\
\text { (total) }\end{array}$ & $\begin{array}{r}\text { Number of } \\
\text { treated }\end{array}$ & $\begin{array}{r}\text { Number of } \\
\text { untreated }\end{array}$ \\
\hline \pm 6 months & 0.1305 & 0.0028 & 0.0075 & 414 & 216 & 198 \\
\pm 5 months & 0.1225 & 0.0123 & 0.0190 & 363 & 193 & 170 \\
\pm 4 months & 0.1364 & 0.0077 & 0.0194 & 292 & 157 & 135 \\
\pm 3 months & 0.0871 & 0.0773 & 0.1917 & 227 & 124 & 103 \\
\pm 2 months & 0.1534 & 0.0415 & 0.0595 & 154 & 87 & 67 \\
\pm 1 month & 0.2593 & 0.0101 & 0.0374 & 66 & 39 & 27 \\
\hline
\end{tabular}

Note: See Section 3.2 about the implementation of randomization tests. 


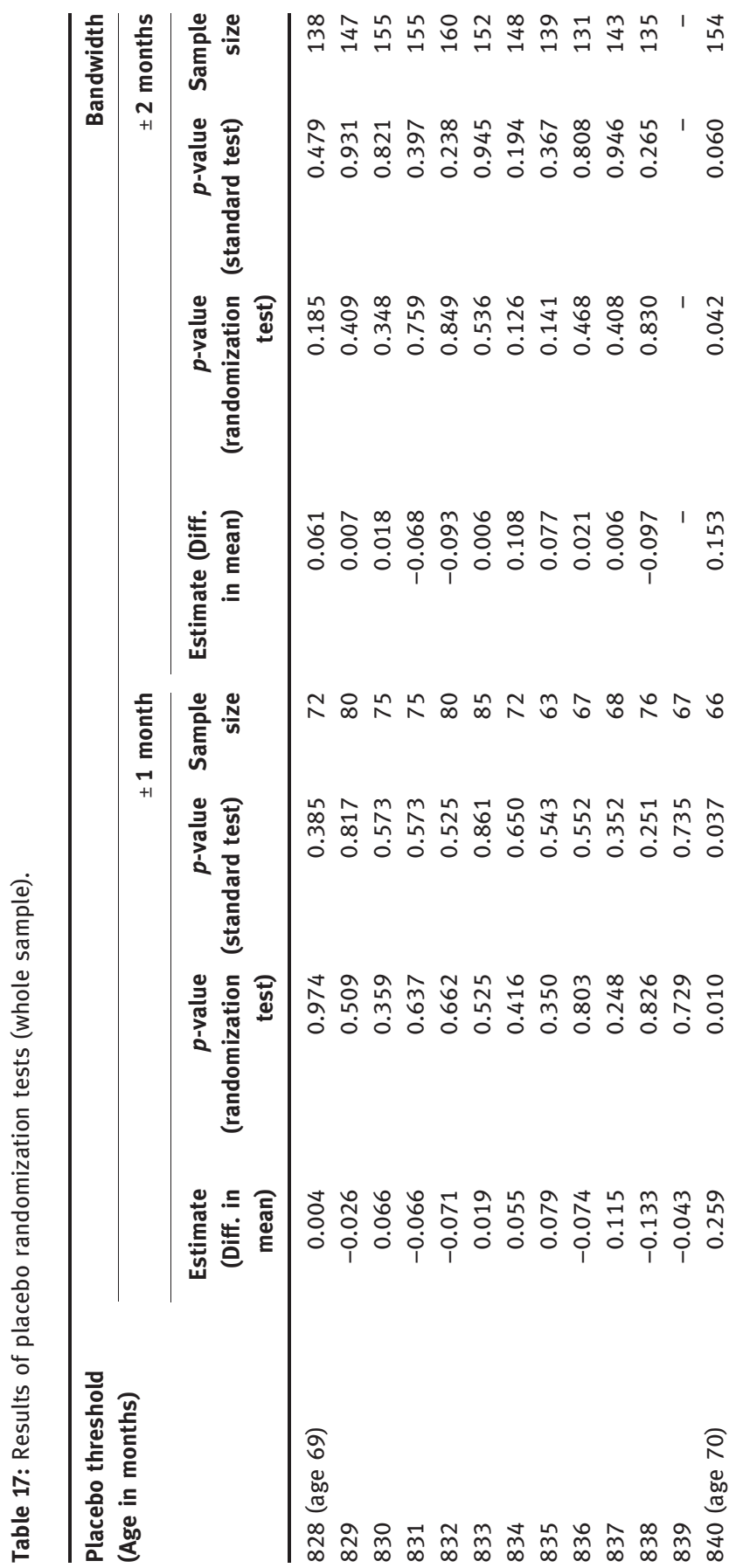




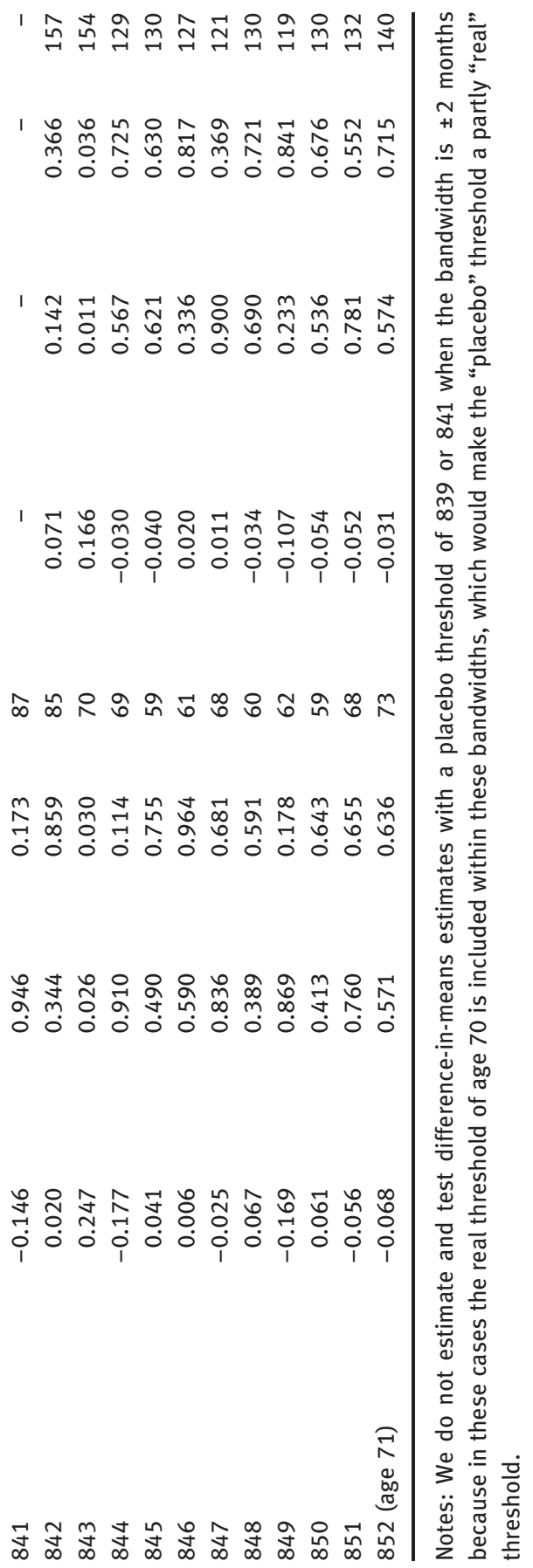


Table 18: RD estimates for subjective chewing ability (whole sample).

\begin{tabular}{lrrrr}
\hline \multirow{2}{*}{ Polynomial order } & \multicolumn{3}{c}{ Bandwidth } \\
\cline { 2 - 5 } & $\pm \mathbf{6 0}$ months & $\pm \mathbf{2 4}$ months & $\pm \mathbf{1 2}$ months & $\pm \mathbf{6}$ months \\
\hline \multirow{2}{*}{ One } & & & Unrestricted chewing ability \\
& -0.001 & -0.013 & -0.001 & -0.016 \\
Two & $(0.027)$ & $(0.034)$ & $(0.044)$ & $(0.044)$ \\
\multirow{3}{*}{ Three } & 0.023 & -0.012 & -0.047 & -0.103 \\
& $(0.032)$ & $(0.043)$ & $(0.040)$ & $(0.070)$ \\
& -0.011 & 0.004 & -0.024 & -0.014 \\
One & $(0.037)$ & $(0.063)$ & $(0.095)$ & $(0.148)$ \\
& & & & Restricted chewing ability \\
Two & -0.003 & 0.001 & -0.014 & -0.044 \\
& $(0.013)$ & $(0.019)$ & $(0.024)$ & $(0.025)$ \\
Three & -0.010 & -0.021 & -0.041 & $-0.089^{*}$ \\
& $(0.017)$ & $(0.028)$ & $(0.026)$ & $(0.048)$ \\
Covariates & -0.001 & -0.038 & $-0.076^{*}$ & -0.055 \\
Sample size & $(0.024)$ & $(0.031)$ & $(0.038)$ & $(0.075)$ \\
\hline
\end{tabular}

Notes: ${ }^{\star \star \star}$, ${ }^{\star \star}$, and ${ }^{*}$ denote significance at the $1 \%, 5 \%$, and $10 \%$ level respectively. A robust standard error clustered by age in months is presented in parentheses.

\section{Appendix G: Difference-in-Differences Estimates}

Table 19: DID estimates.

\begin{tabular}{|c|c|c|c|c|c|c|}
\hline \multirow{2}{*}{$\begin{array}{l}\text { Sample } \\
\text { Control group }\end{array}$} & \multirow[b]{2}{*}{ Younger } & All & \multicolumn{2}{|r|}{ Men } & \multicolumn{2}{|r|}{ Women } \\
\hline & & Older & Younger & Older & Younger & Older \\
\hline \multirow[t]{2}{*}{ DID estimate } & $0.042^{\star}$ & 0.050 * & 0.046 & 0.011 & 0.037 & $0.086^{\star *}$ \\
\hline & $(0.023)$ & $(0.027)$ & $(0.031)$ & $(0.037)$ & $(0.034)$ & $(0.039)$ \\
\hline Sample size & 3,231 & 998 & 1,689 & 487 & 1,542 & 511 \\
\hline Adj. R-squared & 0.001 & 0.004 & 0.001 & -0.002 & 0.000 & 0.009 \\
\hline
\end{tabular}

Notes: ${ }^{\star \star *}$, ${ }^{\star *}$, and $*$ denote significance at the $1 \%, 5 \%$, and $10 \%$ level respectively. A robust standard error is presented in parentheses. The "younger" control group consists of the people who have not yet crossed the threshold of age 70 during the sample period (i.e. age 50-69) and the "older" control group consists of the people who have already crosssed the threshold before the sample period (i.e. age 70-79). 


\section{References}

Baicker, K., and D. Goldman. 2011. "Patient Cost-Sharing and Healthcare Spending Growth." Journal of Economic Perspectives 25 (2):47-68.

Baicker, K., S. L. Taubman, H. L. Allen, M. Bernstein, J. H. Gruber, J. P. Newhouse, E. C. Schneider, B. J. Wright, A. M. Zaslavsky, and A. N. Finkelstein. 2013. "The Oregon Experiment: Effects of Medicaid on Clinical Outcomes." New England Journal of Medicine 368 (18):1713-22.

Barreca, A. I., M. Guldi, J. M. Lindo, and G. R. Waddell. 2011. "Saving Babies? Revisiting the Effect of Very Low Birth Weight Classification." The Quarterly Journal of Economics 126 (4):2117-23.

Buchmueller, T. C., S. Miller, and M. Vujicic (2014) "How Do Providers Respond to Public Health Insurance Expansions? Evidence From Adult Medicaid Dental Benefits," NBER Working Paper 20053.

Buchmueller, T. C., S. Orzol, and L. D. Shore-Sheppard. 2015. "The Effect of Medicaid Payment Rates on Access to Dental Care Among Children." American Journal of Health Economics 1 (2):194-223.

Calonico, S., M. D. Cattaneo, and R. Titiunik. 2014. "Robust Nonparametric Confidence Intervals for Regression-Discontinuity Designs.” Econometrica 82 (6):2295-326.

Cattaneo, M. D., B. R. Frandsen, and R. Titiunik. 2014. "Randomization Inference in the Regression Discontinuity Design: An Application to Party Advantages in the U.S. Senate." Journal of Causal Inference 3 (1):1-24.

Choi, M. K. 2011. "The Impact of Medicaid Insurance Coverage on Dental Service Use." Journal of Health Economics 30 (5):1020-31.

Bertea, C., K. S. Paola, J. Dratva, and E. Z. Stutz. 2007. “Female Gender Is Associated with Dental Care and Dental Hygiene, but Not with Complete Dentition in the Swiss Adult Population." Journal of Public Health 15 (5):361-7.

Courtemanche, C. J., and D. Zapata. 2014. "Does Universal Coverage Improve Health? The Massachusetts Experience." Journal of Policy Analysis and Management 33 (1): 36-69.

Decker, S. L. 2011. "Medicaid Payment Levels to Dentists and Access to Dental Care Among Children and Adolescents." The Journal of the American Medical Association 306 (2): 187-93.

Decker, S. L., and B. J. Lipton. 2015. "Do Medicaid Benefit Expansions Have Teeth? The Effect of Medicaid Adult Dental Coverage on the Use of Dental Services and Oral Health." Journal of Health Economics 44:212-25.

Eklund, S. A., J. L. Pittman, and S. J. Clark. 2003. “Michigan Medicaid's Healthy Kids Dental Program: An Assessment of the First 12 Months." The Journal of the American Dental Association 134 (11):1509-15.

Finkelstein, A., S. Taubman, B. Wright, M. Bernstein, J. Gruber, J. P. Newhouse, H. Allen, and K. Baecker. 2012. "The Oregon Health Insurance Experiment: Evidence From the First Year." Quarterly Journal of Economics 127 (3):1057-106.

Fukushima, K., S. Mizuoka, S. Yamamoto, and T. lizuka. 2015. "Patient Cost Sharing and Medical Expenditures for the Elderly." Journal of Health Economics 45:115-130.

Gelman, A., and G. Imbens (2014) "Why High-Order Polynomials Should Not Be Used in Regression Discontinuity Designs," NBER Working Paper 20405. 
Glied, S., and M. Neidell. 2010. "The Economic Value of Teeth." Journal of Human Resources 45 (2):468-96.

Hahn, J., P. Todd, and W. Van der Klaauw. 2001. "Identification and Estimation of Treatment Effects with a Regression-Discontinuity Design." Econometrica 69 (1):201-9.

Hay, J. W., H. Bailit, and D. A. Chiriboga. 1982. "The Demand for Dental Health.” Social Science \& Medicine 16 (13):1285-9.

Ho, D. E., and K. Imai. 2006. "Randomization Inference with Natural Experiments: An Analysis of Ballot Effects in the 2003 California Recall Election." Journal of the American Statistical Association 101 (475):888-900.

Hughes, R. J., P. C. Damiano, M. J. Kanellis, R. Kuthy, and R. Slayton. 2005. “Dentists' Participation and Childrens' Use of Services in the Indiana Dental Medicaid Program and SCHIP: Assessing the Impact of Increased Fees and Administrative Changes." The Journal of the American Dental Association 136 (4):517-23.

Ikegami, N., B. -K. Yoo, H. Hashimoto, M. Matsumoto, H. Ogata, A. Babazono, R. Watanabe, K. Shibuya, B. -M. Yang, M. R. Reich, et al. 2011. "Japanese Universal Health Coverage: Evolution, Achievements, and Challenges.” The Lancet 378 (9796): 1106-15.

Ikenwilo, D. 2013. "A Difference-in-Differences Analysis of the Effect of Free Dental Check-Ups in Scotland." Social Science \& Medicine 83:10-18.

Imbens, G., and K. Kalyanaraman. 2012. "Optimal Bandwidth Choice for the Regression Discontinuity Estimator.” The Review of Economic Studies 79 (3):933-59.

Imbens, G. W., and J. M. Wooldridge. 2009. "Recent Developments in the Econometrics of Program Evaluation.” Journal of Economic Literature 47 (1):5-86.

Kawaguchi, D. 2011. "Actual Age at School Entry, Educational Outcomes, and Earnings.” Journal of the Japanese and International Economies 25 (2):64-80.

Kiil, A., and K. Houlberg. 2014. "How Does Copayment for Health Care Services Affect Demand, Health and Redistribution? a Systematic Review of the Empirical Evidence From 1990 to 2011." The European Journal of Health Economics 15 (8):813-28.

Kreider, B., R. J. Manski, J. Moeller, and J. Pepper. 2015. "The Effect of Dental Insurance on the Use of Dental Care for Older Adults: A Partial Identification Analysis." Health Economics 24 (n):840-858.

Kwan, S., and P. E. Petersen. 2010. "Oral Health: Equity and Social Determinants." In Equity, Social Determinants and Public Health Programmes, Chap. 9, edited by E. Blas and

A. Sivasankara Kurup, 159-76. Geneva: World Health Organization.

Lee, D. S. 2008 "Randomized Experiments From Non-Random Selection in U.S. House Elections.” Journal of Econometrics 142 (2):675-97.

Lee, D. S., and D. Card. 2008. "Regression Discontinuity Inference with Specification Error." Journal of Econometrics 142 (2):655-74.

Lee, D. S., and T. Lemieux. 2010. "Regression Discontinuity Designs in Economics." Journal of Economic Literature 48 (2):281-355.

Levy, H., and D. Meltzer. 2008. "The Impact of Health Insurance on Health." Annual Review of Public Health 29 (1):399-409.

Listl, S., J. Galloway, P. A. Mossey, and W. Marcenes. 2015. "Global Economic Impact of Dental Diseases." Journal of Dental Research 94 (10):1355-61.

Listl, S., J. Moeller, and R. Manski. 2014. "A Multi-Country Comparison of Reasons for Dental Non-Attendance." European Journal of Oral Sciences 122 (1):62-9. 
Manning, W. G., H. L. Bailit, B. Benjamin, and J. P. Newhouse. 1985. "The Demand for Dental Care: Evidence From a Randomized Trial in Health Insurance." The Journal of the American Dental Association 110 (6):895-902.

Manning, W. G., H. L. Bailit, B. Benjamin, and J. P. Newhouse (1986) "The Demand for Dental Care: Evidence From a Randomized Trial in Health Insurance,” Technical Report R-3225-HHS.

Manning, W. G., and C. E. Phelps. 1979. "The Demand for Dental Care.” The Bell Journal of Economics 10 (2):503-25.

Matsuyama, Y., J. Aida, K. Takeuchi, G. Tsakos, R. G. Watt, K. Kondo, and K. Osaka. 2014. “Inequalities of Dental Prosthesis Use Under Universal Healthcare Insurance." Community Dentistry and Oral Epidemiology 42 (2):122-8.

McCrary, J. 2008. "Manipulation of the Running Variable in the Regression Discontinuity Design: A Density Test.” Journal of Econometrics 142 (2):698-714.

Meyerhoefer, C. D., S. H. Zuvekas, and R. Manski. 2014. "The Demand for Preventive and Restorative Dental Services.” Health Economics 23 (1):14-32.

MHLW. 2011. "Survey of Dental Diseases (Shika Shikkan Jittai Chosa)." Accessed on February 23, 2015. http://www.mhlw.go.jp/toukei/list/62-17.html.

Mueller, C. D., and A. C. Monheit. 1988. "Insurance Coverage and the Demand for Dental Care: Results for Non-Aged White Adults." Journal of Health Economics 7 (1):59-72.

Nasseh, K., and M. Vujicic. 2013. "Health Reform in Massachusetts Increased Adult Dental Care Use, Particularly Among the Poor." Health Affairs 32 (9):1639-45.

Newhouse, J. 1993. Free for All: Lessons From the RAND Health Insurance Experiment. Cambridge, MA: Harvard University Press.

Nishi, A., J. M. McWilliams, H. Noguchi, H. Hashimoto, N. Tamiya, and I. Kawachi. 2012. "Health Benefits of Reduced Patient Cost Sharing in Japan." Bulletin of the World Health Organization 90:426-435.

OECD. 2011. "Health at a Glance 2011," http://www.oecd.org/els/healthsystems/49105858.pdf, Accessed on February 23, 2015.

Petersen, P. E., D. Bourgeois, H. Ogawa, S. Estupinan-Day, and C. Ndiaye. 2005. "The Global Burden of Oral Diseases and Risks to Oral Health." Bulletin of the World Health Organization 83 (9):661-9.

Petersen, P. E., and T. Yamamoto. 2005. "Improving the Oral Health of Older People: The Approach of the WHO Global Oral Health Programme." Community Dentistry and Oral Epidemiology 33 (2):81-92.

Rosenbaum, P. R. 2002. Observational Studies, Springer Series in Statistics. New York: Springer-Verlag.

Rosenbaum, P. R. 2010. Design of Observational Studies, Springer Series in Statistics. New York: Springer-Verlag.

Shigeoka, H. 2014a. "The Effect of Patient Cost Sharing on Utilization, Health, and Risk Protection.” American Economic Review 104 (7):2152-84.

Shigeoka, H. 2014b. "School Entry Cut-Off Date and Timing of Births." Working paper.

Singhal, S., R. Correa, and C. Quinonez. 2013. "The Impact of Dental Treatment on Employment Outcomes: A Systematic Review." Health Policy 109 (1):88-96.

Sintonen, H., and I. Linnosmaa. 2000. "Economics of Dental Services." In Handbook of Health Economics, 1 of Handbook of Health Economics, Chap. 24, edited by A. J. Culyer and J. P. Newhouse, 1251-96. North Holland: Elsevier. 
Sommers, B. D., S. K. Long, and K. Baicker. 2014. "Changes in Mortality After Massachusetts Health Care Reform: A Quasi-Experimental Study-Changes in Mortality After Massachusetts Health Care Reform." Annals of Internal Medicine 160 (9):585-93.

Ueno, M., T. Yanagisawa, K. Shinada, S. Ohara, and Y. Kawaguchi. 2008. "Masticatory Ability and Functional Tooth Units in Japanese Adults." Journal of Oral Rehabilitation 35 (5): 337-44.

Ueno, M., S. Ohara, M. Inoue, S. Tsugane, and Y. Kawaguchi. 2012. “Association Between Education Level and Dentition Status in Japanese Adults: Japan Public Health Center-Based Oral Health Study." Community Dentistry and Oral Epidemiology 40 (6):481-7.

Wallace, N. T., M. J. Carlson, D. M. Mosen, J. J. Snyder, and B. J. Wright. 2011. "The Individual and Program Impacts of Eliminating Medicaid Dental Benefits in the Oregon Health Plan." American Journal of Public Health 101 (11):2144-50.

Wang, H., E. C. Norton, and R. Gary Rozier. 2007. "Effects of the State Children's Health Insurance Program on Access to Dental Care and Use of Dental Services." Health Service Review 42 (4):1544-63. 